\title{
New association schemes for mono-ethylene glycol: Cubic-Plus-Association parameterization and uncertainty analysis
}

\author{
Kruger, Francois; Kontogeorgis, Georgios M.; von Solms, Nicolas
}

Published in:

Fluid Phase Equilibria

Link to article, DOI:

10.1016/j.fluid.2017.11.026

Publication date:

2018

Document Version

Peer reviewed version

Link back to DTU Orbit

Citation (APA):

Kruger, F., Kontogeorgis, G. M., \& von Solms, N. (2018). New association schemes for mono-ethylene glycol: Cubic-Plus-Association parameterization and uncertainty analysis. Fluid Phase Equilibria, 458, 211-233. https://doi.org/10.1016/j.fluid.2017.11.026

\section{General rights}

Copyright and moral rights for the publications made accessible in the public portal are retained by the authors and/or other copyright owners and it is a condition of accessing publications that users recognise and abide by the legal requirements associated with these rights.

- Users may download and print one copy of any publication from the public portal for the purpose of private study or research.

- You may not further distribute the material or use it for any profit-making activity or commercial gain

- You may freely distribute the URL identifying the publication in the public portal 


\section{Accepted Manuscript}

New association schemes for mono-ethylene glycol: Cubic-Plus-Association parameterization and uncertainty analysis

Francois Kruger, Georgios M. Kontogeorgis, Nicolas von Solms

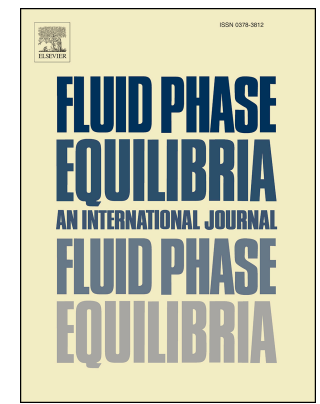

PII:

S0378-3812(17)30464-8

DOI:

10.1016/j.fluid.2017.11.026

Reference: $\quad$ FLUID 11661

To appear in: Fluid Phase Equilibria

Received Date: 12 August 2017

Revised Date: 5 November 2017

Accepted Date: 16 November 2017

Please cite this article as: F. Kruger, G.M. Kontogeorgis, N. von Solms, New association schemes for mono-ethylene glycol: Cubic-Plus-Association parameterization and uncertainty analysis, Fluid Phase Equilibria (2017), doi: 10.1016/j.fluid.2017.11.026.

This is a PDF file of an unedited manuscript that has been accepted for publication. As a service to our customers we are providing this early version of the manuscript. The manuscript will undergo copyediting, typesetting, and review of the resulting proof before it is published in its final form. Please note that during the production process errors may be discovered which could affect the content, and all legal disclaimers that apply to the journal pertain. 


\section{New Association Schemes for Mono-Ethylene Glycol}

Cubic-Plus-Association parameterization and uncertainty analysis

Francois Kruger, Georgios M. Kontogeorgis, Nicolas von Solms*

* Corresponding author

Email: nvs@kt.dtu.dk

Center for Energy Resources Engineering

Department of Chemical and Biochemical Engineering

Technical University of Denmark (DTU)

DK-2800 Lyngby, Denmark

\section{DTU Chemical Engineering}

Department of Chemical and Biochemical Engineering 


\section{Abstract}

Accurate thermodynamic predictions for systems containing glycols are essential for the design and commissioning of novel subsea natural gas dehydration units. Previously it has been shown that the CubicPlus-Association (CPA) equation of state can be used to model VLE, SLE and LLE for mixtures of interest to this application. Recent developments for association schemes have shown that the use of a binary association site provided improvement for the modelling of 1-alkanols. In this work, we implement the binary association site for mono-ethylene glycol (MEG) by proposing three new association schemes (3C, $4 \mathrm{E}$ \& 4F). New parameter sets have been regressed and uncertainty analysis, using the bootstrap methodology, was performed to obtain $95 \%$ confidence intervals for each parameter. An improved parameter set for the literature $4 \mathrm{C}$ scheme was also determined.

The four association schemes were tested against eight data types, with single parameter sensitivity analysis showing that new parameter sets are near optimal. The $3 \mathrm{C}$ scheme provides the best results for pure component properties and the liquid phase of MEG- $\mathrm{H}_{2} \mathrm{O}$, while new $4 \mathrm{C}$ parameters provide the best results for the MEG- $\mathrm{H}_{2} \mathrm{O}$ (vapour phase) and MEG- $n \mathrm{C}_{7}$ LLE. For the limited ternary $\left(\mathrm{MEG}-\mathrm{H}_{2} \mathrm{O}-\mathrm{CH}_{4}\right)$ data and MEG- $n \mathrm{C}_{6} \mathrm{LLE}$, the best results are achieved using the $4 \mathrm{~F}$ scheme. Ternary modelling performance was further improved by using binary interaction parameters fitted to binary vapour phase data.

While each of the new parameter sets provided an improvement over the literature parameters, it was found that no specific scheme was universally the best option. Given the uncertainty ranges and inconsistency between literature data, additional experimental data are required.

Despite the lack of sufficient data, the value of the bootstrap method has been highlighted, both for finding improved parameter sets and transferring uncertainty from experimental data through to thermodynamic and process models. 


\section{Graphical abstract}

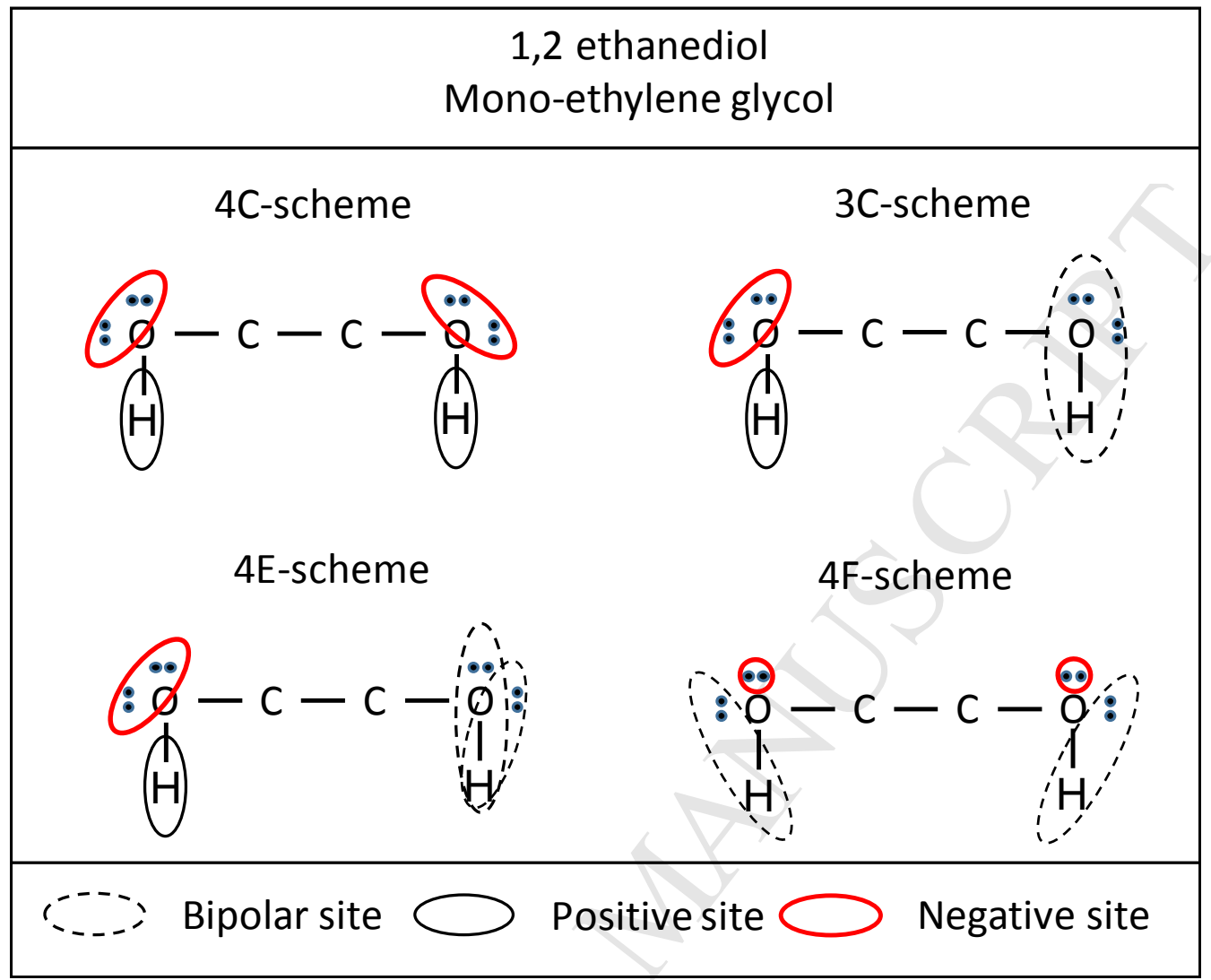

Keywords: cubic-plus-association; parameterization; uncertainty analysis; glycols; new association scheme

\section{Highlights}

- Bootstrap methodology provides excellent mechanism for transference of uncertainty from experimental data to thermodynamic models

- Three new association schemes proposed for MEG

- Improved 4 C parameters

- The new 4F scheme provides the best overall results for natural gas dehydration applications 


\section{Introduction}

The presence of water in natural gas and fuel gas pipelines presents a significant risk to continuous operability. Gas hydrate formation can cause pipelines to be completely blocked, while the combination of condensed water with carbon dioxide and hydrogen leads to corrosion [1]. Gas dehydration through absorption into tri-ethylene glycol (TEG) has become the natural gas industry standard for solving this problem, while mono-ethylene glycol (MEG) and methanol are also considered for direct injection applications due to their flow properties [2] and advantageous cost [3]. Other processing options, such as adsorption, refrigeration, membrane permeation and supersonic processing are available, but have several disadvantages for upstream and offshore applications [4]. Adsorption is typically preferred for ultradehydration applications, but has higher capital costs and a larger plant footprint. Refrigeration requires significant pressure drops to generate sufficient cooling. Use of membranes for water removal has seen some commercial implementation, although economically significant amounts of methane are lost along with the water [5]. Supersonic separators [6] offer interesting advantages for offshore applications, but along with membrane separators [7], are still very much in development and are unlikely to see significant market penetration in the near future [4].

For absorption into liquid desiccants, TEG provides greater dew point depression capability, while direct injection with MEG provides sufficient dehydration and hydrate inhibition for flow assurance and operability. This is of particular interest in subsea networks, where essentially untreated gas is transported over long distances to central processing facilities. Occasionally di-ethylene glycol (DEG) or MEG/DEG mixtures are used to negate the higher relative volatility of MEG (which leads to losses to the gas phase), but these types of installations are less common. Statoil is currently developing the Gas-2-Pipe ${ }^{\mathrm{TM}}$ process [8], which aims to produce on-specification export gas (or Sales Gas) at the seabed. The main specifications are the hydrocarbon dew point, water dew point and glycol content of the gas according to the GASSCO 
specifications [9], while the processing conditions between $50-150$ bar, $5{ }^{\circ} \mathrm{C}(278 \mathrm{~K})$ and glycol content $>90$ wt\% are envisioned.

Proper design of dehydration and hydrate inhibition processes requires a combination of a high quality experimental data and thermodynamic models. The scarcity of data for systems of interest to this investigation has been highlighted in several sources $[3,10-13]$ and very often the available data are contradictory. Additionally, the gas phase quantification of glycols at operating temperatures and pressures is especially challenging as these compounds occur in the low ppm range, which is near the detection limits of gas chromatography [14].

The Cubic-Plus-Association (CPA) $[15,16]$ equation of state (EOS) has been previously implemented for the thermodynamic modelling of gas-water-glycol and gas-condensate-water-glycol systems. CPA is a fiveparameter equation of state which combines the repulsive and attractive terms of the Soave-RedlichKwong (SRK) [17] with the association term first proposed by Wertheim [18-21] and later implemented in an engineering form by Chapman et al. [22,23] into the Statistical Associating Fluid Theory (SAFT) equation(s) of state. The association term is used to account for intermolecular hydrogen-bonding using a site-specific scheme which must be defined for each molecule. Traditionally, alcohols have been described with the $2 \mathrm{~B}$ scheme (1 positive and 1 negative site), while glycols and water have been represented with the $4 \mathrm{C}$ scheme ( 2 positive and 2 negative sites). For almost twenty years, there were relatively few developments with respect to association schemes. However in 2009 [24] and 2011 [25], new association schemes were proposed for glycols (6D) and 1-alcohols (2C). The $2 \mathrm{C}$ scheme of de Villiers et al. [25] is especially interesting as it makes use of the binary site (universal bonder), which had previously only been applied for acid dimerization (1A scheme). 
More recently the need has arisen for robust quantification of the uncertainty and/or sensitivity analysis of both experimental data and thermodynamic models as applied in process design. As Mathias [26] points out: "Several studies have illustrated the effects of uncertainty in the physical-property models on process design, however these publications do not provide an effective way to quantify the propagation of the property uncertainty into design variability." Despite this need and the obvious advantages of understanding modelling uncertainty, Mathias notes that uncertainty analysis has seen limited implementation in industry. Mathias proposed a method for incorporating property uncertainty as a perturbation to the activity coefficient, using an adjustable parameter to give the magnitude of the perturbation. Asprion et al. [27] applied this concept to equations of state by perturbation of the fugacity coefficient.

Another approach was taken by Bjørner et al. [28], who applied a statistical method - called bootstrapping to determine the confidence intervals for the parameterization of $\mathrm{CO}_{2}$ within different variations of CPA. While this method appears more complex, the implementation is relatively straight-forward and has the added advantage of using experimental data (rather than adjustable parameters) to determine the confidence intervals or uncertainty.

Within this work, we build on the work of de Villiers et al. [25] by proposing new association schemes for glycols which incorporate the binary association site. Necessarily, new parameter sets must be regressed, for which the bootstrapping technique is applied for determining parameter confidence intervals. A thorough evaluation of the literature data is required, which will focus on light hydrocarbon, water and glycol mixtures - as the application of this work is natural gas dehydration. Higher hydrocarbons will however not be ignored, as their present risk to both operability within the dehydration process and asset management of downstream transport networks $[14,29]$. 


\section{Literature Review}

\subsection{Literature data of interest to glycol-based dehydration studies}

Both pure component $\left(P_{S A T}\right.$ and $\left.\rho\right)$ and mixture data (binary LLE) have been identified as critical for the evaluation of model parameter sets [30]. As this work is geared towards natural gas dehydration applications, good modelling of glycol-water and natural gas-glycol-water systems (necessary for the design of the absorber and regeneration processes) are focussed on.

In terms of determining process feasibility, the measurement of water and glycol in the vapour phase are essential as these are critical specifications for the final gas product. Overprediction could lead to the rejection of perfectly acceptable process configurations, while underprediction will result in off-spec production and/or downstream asset integrity issues. The lack of experimental data (especially for MEG in the vapour phase) is due to the difficulty of measuring low levels of MEG using standard gas chromatography.

Gas solubility data are very important for the determination of hydrocarbon carryover into the regeneration processes and the subsequent emissions there [31]. For this purpose, other studies have also investigated mixtures including aromatic (BTEX) compounds [10,32].

\subsubsection{Pure component data}

For many studies, the DIPPR correlations (which are fitted to multiple experimental data) have been used to generate pseudo-experimental data at equally spaced intervals for reduced temperature $\left(T_{R}\right)$ ranges of approximately 0.4-0.9. Figure 1 highlights the degree to which the correlations are extrapolated beyond the experimental data (for MEG), with $95 \%$ of the vapour pressure and density points below $T_{R}=0.67$ and 0.58 respectively. For reference, the proposed subsea dehydration would occur between 273-303 K (depending 
on the location of the installation) (approximately $0.38<T_{R}<0.42$ ), while regeneration typically occurs at higher temperatures (up to $\sim 473 \mathrm{~K}$ which is $\mathrm{T}_{\mathrm{R}}=0.66$ ). Very few data are available around $\mathrm{T}_{\mathrm{R}}=0.4-$ especially for glycol vapour pressure, as the experimental values become very low and exceedingly difficult to quantify accurately.

Recent work by Crespo et al. [33] provides high pressure density data up to 950 bar and $363 \mathrm{~K}$ for several glycols including MEG and TEG.

\subsubsection{Binary data}

While there are several pure component data available for vapour pressure and density (if not in the desired ranges always), there are serious concerns with respect to binary, ternary and multicomponent data. For MEG-CH , only Folas et al. [14] quantify both phases. Only for three data points were measured however, making thermodynamic consistency tests impractical. Furthermore, several sources from the open literature have measured $\mathrm{CH}_{4}$ solubility in MEG [14,34-38], but only three (Folas et al. [14], Bersås [39] and Miguens et al. [40]) present data for glycol in the vapour phase. These three data sets share a common genealogy in that they stem from the same research/experimental facilities, albeit spread over at least a decade. Given this development over time, the latest data are likely to be the most accurate - as is also reflected in the quoted experimental error. A comparison of the data is provided in Figure 2.

Figure 2 does not show the data for temperatures above $298 \mathrm{~K}$ as these are not of interest to this study. The figure also shows five isotherms $(273,278,283,293$ and $298 \mathrm{~K}$ with temperature increasing from the lowest to the highest trend) calculated with the CPA equation of state using the parameters derived by Derawi et al. [30]. Inconsistencies in the data of Folas et al. [14] are highlighted for instance by lower gas phase content at $278 \mathrm{~K}$ (versus other data at $283 \mathrm{~K}$ ) and at the point at 100 bar and $298 \mathrm{~K}$. However, most of the rest of the data are consistent with each other and from a modelling perspective we see that the CPA 
model captures the general behaviour of the data, although increasing deviations are observed at higher pressures and temperatures.

For the gas solubility in the liquid phase, there is sufficient overlap for comparison (see Figures 3 and 4) between the various sources.

In Figure 3, three different data sources are shown for higher temperatures, and pressures, relevant to natural gas dehydration. While low experimental uncertainties are claimed (Jou et al. [34].: 2-3\%, Zheng et al. [35]: "Close agreement with Jou et al.", Galvoa et al. [38]: previous work estimates 2-20\% error for their equipment), several inconsistencies are apparent:

- Considerably different solubilities were measured e.g. at 100 bar and $373 \mathrm{~K}$ :

- 10\% difference between Zheng et al. [35] and Jou et al. [34]

○ 40-50\% difference between Galvoa et al. [38] and Jou et al. [34] / Zheng et al. [35]

- Interestingly, only minor differences are observed for MEG- $\mathrm{CO}_{2}$ between these publications

- Below 40 bar, it becomes difficult to distinguish between the solubility profiles for $323 \mathrm{~K}$ and $373 \mathrm{~K}$ suggesting that there exists no significant temperature dependency in this region

- The gradients of the solubility profiles are quite different between the various sources:

- At 100 bar, Folas et al. [14] agrees with Jou et al. [34]

- At 50 bar, Folas et al. [14] is roughly between Jou et al. [34] and Zheng et al. [35]

- Galvoa et al. [38] appears more linear (at least over a larger pressure range) than the other sources)

Both Wang et al. [36] and Abdi et al. [37] measured $\mathrm{CH}_{4}$ solubility in MEG for verification purposes comparing to Zheng et al. [35] and Jou et al. [34] respectively. Abdi et al. show roughly a 0.001-0.0015 $\mathrm{mol} / \mathrm{mol}$ deviation from Jou et al. [34]. Very low experimental uncertainties are quoted, with the mole fraction error given as 0.0001 . It is also noted that only $45-60$ minutes were allowed for equilibrium to be 
attained, which may explain the lower solubilities as compared to other sources. Wang et al. [36] report a maximum deviation between parallel runs of $5 \%$, although their binary data do not match well with other literature sources (Figure 4).

Given the importance of accurately predicting LLE data [30], it is also necessary to consider these data in the study. Derawi et al. [41] measured seven binary mixtures, including MEG-nC$C_{6}$ and MEG- $n C_{7}$, at temperatures between 305 and $353 \mathrm{~K}$ and 1 bar. Razzouk et al. [42] published a correction of earlier results for LLE, which also included MEG- $n C_{6}$ and later data [43] from the same research group provided fourteen binary systems, including MEG- $n C_{7}$. The MEG- $n C_{6}$ data are compared in Figure 5 , where the logarithmic scale must be kept in mind to correctly compare the data. MEG solubility in hydrocarbon-rich phase $\left(\mathrm{x}_{1}{ }^{\prime \prime}\right.$ in Figure 5) data are similar, but significantly higher values ( 30-40\%) were found for hydrocarbon solubility in MEG $\left(x_{2}^{\prime}\right)$. With linear extrapolation of the data from Derawi et al. to lower temperatures, significant differences for both datasets occur.

Significantly fewer discrepancies are observed in the literature data for MEG- $\mathrm{H}_{2} \mathrm{O}$ VLE, although most of these data are measured at conditions outside the range of interest for dehydration and are more applicable for glycol regeneration: low pressure (<1 bar) and high temperature ( $>350 \mathrm{~K})$.

Although natural gas is predominantly composed of methane, other components such as ethane, nitrogen and carbon dioxide may occur in significant quantities. MEG- $\mathrm{C}_{2} \mathrm{H}_{6}$ was measured by both Wang et al. [36] and Jou et al. [44]. Although no common data ranges were measured, the deviations between these data are estimated at $>35 \% . \mathrm{CO}_{2}$ solubility in MEG has been studied by several authors [35,45-48], generally at high glycol content and with only few data below $300 \mathrm{~K}$ being available. Zheng et al. [35] are the only source for MEG- $\mathrm{N}_{2}$ measurements, with data at 323,373 and $398 \mathrm{~K}$ available. 


\subsubsection{Multicomponent data}

Very few multicomponent data sets, which include glycols, exist in the open literature and often the data measured for MEG-related studies use 50-60 wt\% aqueous solutions. These solutions are of interest for hydrate inhibition applications [43], but contain significantly more water than what would be desired for dehydration applications. Of those available, the following are of specific interest to this work:

Abdi et al. [37] measured gas solubility $\left(\mathrm{CH}_{4} / \mathrm{CO}_{2} / \mathrm{N}_{2}\right)$ in ternary mixtures with aqueous MEG (40 and 60 wt\%) at 150 and 200 bar and 263 and $283 \mathrm{~K}$. These data are outside the desired pressure and glycol content ranges. Wang et al. [36] also measured gas solubility $\left(\mathrm{CH}_{4} / \mathrm{C}_{2} \mathrm{H}_{6} / \mathrm{CH}_{4}+\mathrm{C}_{2} \mathrm{H}_{6}\right)$ in aqueous MEG (20-100 wt\%) from

50-400 bar and 283-303 K. Folas et al. [14] measured MEG- $\mathrm{H}_{2} \mathrm{O}-\mathrm{CH}_{4}$ for two temperatures (278 \& $298 \mathrm{~K}$ ) and three pressures $(50,100 \& 150$ bar), where a roughly 50 wt\% aqueous MEG solution was used. Both phases are quantified, with $\mathrm{CH}_{4}$ solubility and $\mathrm{H}_{2} \mathrm{O}$ in gas errors estimated at $5 \%$ while the MEG in gas error is given as $25 \%$. Miguens et al. [40] measured the $\mathrm{CH}_{4}-\mathrm{C}_{2} \mathrm{H}_{6}-\mathrm{MEG}$ system for a fixed $85 \mathrm{~mol} \% \mathrm{CH}_{4}$ gas mixture at 273, 283 and $293 \mathrm{~K}$ as well as 50 and 100 bar. The experimental accuracy is given as $+/-10 \%$.

Mokbel et al. [43] also measured data for seven ternary LLE for alkanes with MEG and $\mathrm{H}_{2} \mathrm{O}$ at three temperatures $283,303 \& 323 \mathrm{~K}$, with the $n$-hexane and $n$-heptane data sets being of special interest. MEG and water in mixtures with various aromatics, condensates and oils have also been measured and published [49-52], but these data are not considered in this study as they are not relevant to natural gas dehydration. 
For both MEG and TEG, the Gas Processors' Association (GPA) has several reports (e.g. RR-117, RR-131, RR-137, RR-149, RR-198) which contain experimental data. These data do not include measurements of glycol content in gas, and some references [3] have called into question their accuracy.

\subsection{Thermodynamic modelling of associating systems}

\subsubsection{Development of SAFT-type equations of state for describing systems containing} alcohols/glycols

While the first SAFT paper of Chapman and co-workers [23] presented the framework and equations relating to association, it was Maciej Radosz and Stanley Huang who first proposed (see Figure 6 below) association schemes in Tables 7 and 8 of Equation of State for Small, Large, Polydisperse, and Associating Molecules [53]. Of specific interest to our work, are the $1 \mathrm{~A}, 2 \mathrm{~B}$ and $4 \mathrm{C}$ association schemes which were proposed for acids, alcohols and water respectively. In the naming convention, the number represents the number of association sites while letters were allocated somewhat less consistently to differentiate between the types of interactions between sites. The $1 \mathrm{~A}$ scheme (and A-schemes in general) considers association sites which will be attracted to any other site-type on another molecule. As double "bonding" between two molecules is not allowed in the underlying treatment developed by Wertheim [18-21], the $1 \mathrm{~A}$ scheme was used to approximate the dimerization between acid molecules. In the 2B scheme, two different types of association sites are defined with like-like interactions being zero and unlike interactions being allowed. In the representation of an alcohol, one site would be allocated to the hydrogen (proton) on the hydroxyl while the other is allocated to the lone electron pairs of hydroxyl oxygen. If alcohols are treated in a rigorous fashion, then two separate association sites are defined to represent the two electron lone pairs on the hydroxyl oxygen. Although the underlying mathematical model isn't explicitly based on 
charge/polarization, it has become natural to talk of positive and negative ${ }^{1}$ sites due to the nature of hydrogen bonding/association. The 3B scheme (which is the rigorous physical description of alcohols, but is used almost exclusively for methanol) highlights this fact, where defining the scheme as 1 "positive" and 2 "negative" sites is mathematically identical to the definition of 1 "negative" and 2 "positive" sites. Physically speaking, the former is preferred of course [54]. Relevant association schemes from the early SAFT work are illustrated in Figure 6.

Ideally one would like to evaluate the choice of association schemes through experimental data e.g. spectroscopic methods, but it is difficult to identify specific $\mathrm{OH}$ peaks when water is present in the mixture. An alternative is to use molecular simulations. Olsen et al. [55] evaluated hydrogen bonding for $50 \%$ glycol-water mixtures for temperatures between 275-370 K finding average hydrogen bonds per glycol to be between 1.8-2.5 and 1.6-2.4 for MEG and TEG respectively. Their work indicates a higher degree of selfassociation versus cross-association for glycols in aqueous MEG and TEG, and that for TEG ether oxygens are less involved in hydrogen-bonding than the hydroxyl oxygens. Neutron diffraction data has been used to calculate the average number of hydrogen bonds for water at various conditions [56] finding for instance 3.6 bonds per molecule at ambient conditions. This finding has been used to support the modelling of water with the $4 \mathrm{C}$ association scheme.

CPA was originally proposed in 1996 [15], with an extension to associating mixtures and model simplifications introduced in 1999 [16]. The general form of the model is given by: [57]

$$
\begin{aligned}
P & =S R K_{\text {rep }}+S R K_{\text {att }}+S A F T_{\text {assoc }} \\
& =\frac{R T}{V_{m}-b}-\frac{a(T)}{V_{m}\left(V_{m}+b\right)}-\frac{R T}{2 V_{m}}\left(1+\rho \frac{\partial \ln g}{\partial \rho}\right) \sum_{i} x_{i} \sum_{A_{i}}\left(1-X_{A_{i}}\right)
\end{aligned}
$$

Within the SRK terms above, three parameters are required:

\footnotetext{
${ }^{1}$ Some sources prefer electron donor and electron acceptor to positive and negative
} 
- b: Co-volume $\left[\mathrm{cm}^{3} / \mathrm{mol}\right]$

- $a(T)$ : Soave-type temperature-dependent energy term, which is described by

$$
a(T)=a_{0}\left(1+c_{1}\left(1-\sqrt{T_{R}}\right)\right)^{2}
$$

- $\mathrm{a}_{0}$ : attractive energy term ${ }^{2}\left[\right.$ bar $\left.\mathrm{cm}^{6} / \mathrm{mol}^{2}\right]$

- $\mathrm{c}_{1}$ : attractive energy temperature-correction [dimensionless]

○ $T_{R}$ : the reduced temperature $\left(T / T_{C}\right)$

Association was incorporated into CPA with the SAFT association term in Eq. 1 and the association schemes shown in Figure 6. Association is described through the summation (i) over all molecules for all sites (A) of nonbonded sites $\left(X_{A_{i}}\right) . X_{A_{i}}$ is defined as:

$$
X_{A_{i}}=\frac{1}{1+\rho \sum_{j} x_{j} \sum_{B_{j}}\left(X_{B_{j}} \Delta^{A_{i} B_{j}}\right)}
$$

where the property $\Delta^{A_{i} B_{j}}$ is defined as the association strength between site $\mathrm{A}$ on molecule $\mathrm{i}$ and site $B$ on molecule $\mathrm{j}$, and is described by:

$$
\Delta^{A_{i} B_{j}}=g(\rho)\left[\exp \left(\frac{\varepsilon^{A_{i} B_{j}}}{R T}\right)-1\right] b_{i j} \beta^{A_{i} B_{j}}
$$

Eq. 4 introduces the two final pure component parameters:

- $\varepsilon$ : association energy ${ }^{3}\left[\right.$ bar $\left.\mathrm{cm}^{6} / \mathrm{mol}\right]$

- $\quad \beta$ : association volume [dimensionless]

\footnotetext{
${ }^{2}$ In this work, $a_{0}$ is usually shown in its reduced form as $\Gamma=a_{0} /(b \cdot R)[K]$, where $R$ is the universal gas constant

${ }^{3}$ In this work, the association energy is presented as $\varepsilon / R[K]$
} 
Figure 7 illustrates the bond (dotted line) formed between two alcohol molecules using the 2B scheme, with the bond energy and bond length described $\varepsilon$ and $\beta$. For mixtures, it is necessary to define combining rules for these parameters:

$$
\begin{gathered}
\varepsilon^{A_{i} B_{j}}=\frac{\varepsilon^{A_{i}+\varepsilon^{B_{j}}}}{2} \quad(\mathrm{CR}-1) \\
\beta^{A_{i} B_{j}}=\sqrt{\beta^{A_{i} \beta^{B_{j}}}} \quad(\mathrm{CR}-1) \\
\Delta^{A_{i} B_{j}}=\sqrt{\Delta^{A_{i} \Delta^{B_{j}}}} \quad(\mathrm{ECR})
\end{gathered}
$$

Eq. 7

The ECR and CR-1 mixing rules are relatively similar with the only difference practically speaking that ECR also accounts for the influence of the b-term. ECR has been recommended for MEG- $\mathrm{H}_{2} \mathrm{O}$ systems $[57,58]$.

Combined with the three physical parameters from the SRK terms, this means that CPA has a total of 5 pure component parameters. These parameters are usually fitted to vapour pressure $\left(\mathrm{P}_{\mathrm{SAT}}\right)$ and density $(\rho)$ data, although several options are available: four parameterization approaches are discussed in the original CPA paper [15], spectroscopy data can be used where available $[59,60]$ or the incorporation of binary data (specifically LLE) as was done for example by Derawi et al. [30] for glycols. Several potential issues regarding parameterization have also been identified e.g. identification of the best/correct parameter set among several acceptable sets [61]. The use of LLE data has been advocated as best practice, although without necessarily including it in the parameter estimation procedure i.e. used for selection between competing parameter sets.

Due this interest in modelling glycols for process design applications, five glycols (including MEG and TEG) were parameterized for CPA in 2003 [30]. Several important results are presented:

- The $4 \mathrm{C}$ scheme provides a superior representation for glycols to the $2 \mathrm{~B}$ scheme 
- Multiple parameter sets provide equally good description for glycol pure component properties

- Due to the uncertainty associated with and relative lack of pure component density and vapour pressure data, it is necessary to include some MEG-hydrocarbon liquid-liquid equilibria (LLE) data into the regression algorithm in order to discern the "correct" parameter sets

For the pure component properties, the DIPPR [62] correlations were fitted over a reduced temperature $\left(T_{R}\right)$ range of 0.4-0.9 at equally spaced intervals of 0.01 . Derawi et al. discussed in detail the effect of using different $T_{R}$ ranges and different versions of the DIPPR correlations. Their recommended MEG parameters were fitted to the 2001 DIPPR correlations (which are the same as the most current version) and low absolute average (relative) deviations (\%AARD) were achieved for vapour pressure $\left(\mathrm{P}_{\mathrm{SAT}}\right)$ and liquid density ( $\rho)$. It is noted that all four trial parameter sets used for the $4 \mathrm{C}$ had a b-parameter greater than $50 \mathrm{~cm}^{3} / \mathrm{mol}$. Subsequently to the work done by Derawi et al.[30], Breil and Kontogeorgis [24] proposed a new 6-site association scheme (6D) for TEG which consisted of two "positive" sites and "four" negative sites - with the two additional negative sites representing the electrons of the ether oxygens in the molecular structure. The literature parameters for MEG and TEG are given in Table 1.

In 2011, a new association scheme was proposed by de Villiers et al. [25] for 1-alkanols (methanol to 1-decanol) with parameterization for one of the SAFT variants (sPC-SAFT). This new scheme (2C) combined one "negative" site and one "binary" site (the universal bonding site used in the 1A-scheme). For the regression algorithm objective function, heat of vapourization $\left(\Delta \mathrm{h}_{\text {vap }}\right)$ data were also included and DIPPR correlations are used $\left(0.5<\mathrm{T}_{\mathrm{R}}<0.9\right)$.

\subsubsection{Modelling applications for systems of interest for natural gas dehydration}

Several models may be used for natural gas dehydration applications with equations of state, activity coefficient models and even machine learning applications found in the literature. For this study we are however interested in the SRK-based CPA using a simplified radial distribution [16]. 
CPA is very flexible for systems containing glycols and hydrate-inhibition applications [58]. More complete reviews [58,63-65] as well as a discussion about the limitations of the model [61] are available in the literature. Most CPA-based applications use the 4C scheme and original parameters of Derawi et al. [30] for MEG with the following applications of interest for this work: Folas et al. [14] were able to generate fairly good predictions with CPA for ternary MEG- $\mathrm{H}_{2} \mathrm{O}-\mathrm{CH}_{4}$ systems using interaction parameters fitted to binary data, especially for the $\mathrm{H}_{2} \mathrm{O}$ and MEG in gas phase at pressures up to 200 bar. Miguens et al. [40] have modelled their data using CPA, noting that the model provides good description for $\mathrm{CH}_{4}-\mathrm{C}_{2} \mathrm{H}_{6}-\mathrm{MEG}$ at 50 bar, while larger deviations occur at 100 bar. Simultaneous description of VLE and LLE was obtained for glycols with aromatic compounds and water [10].

In the field of hydrate studies, several data and modelling papers have been published for systems containing MEG modelled with CPA [66-68]. Good results are achieved for the prediction of water content in the vapour phase, although temperature-dependent binary interaction parameters (BIPs) and additional model terms (e.g. van der Waals-Platteeuw term for gas hydrates) were used. For systems containing only natural gas components and water, CPA is shown to be purely predictive (no BIPs used) and comparable performance to the empirical GERG-water correlation has been achieved [69]. CPA has also been used to model more complex reservoir fluids [49-52] although BIP correlations and $\mathrm{C}_{7+}$ characterization methods are implemented. Afzal et al. [70] have measured the infinite dilution activity coefficient for several alkanes $\left(C_{5}-C_{16}\right)$ with four glycols, including MEG and TEG. These data were used for deriving new BIPs, which were quite different from those fitted to LLE data. CPA has also been successfully implemented in industrial process simulators [31] specifically for modelling dehydration and hydrate inhibition systems.

Due to the intricacies of modelling $\mathrm{CO}_{2}$, there have been several studies, including a six-part series [71-76], involving acid gas mixtures $\left(\mathrm{H}_{2} \mathrm{~S} / \mathrm{CO}_{2}\right.$ with alkanes, water, glycols in binary and multicomponent mixtures) and several data are available. The emphasis of this modelling has however been on the description of $\mathrm{H}_{2} \mathrm{~S} / \mathrm{CO}_{2}$ (whether inert, solvating or self-associating) and the mixing rules (and by extension BIPs) with the 
MEG parameters remaining unchanged. Hydrate dissociation curves for multicomponent systems containing $\mathrm{CO}_{2}$ and MEG have also been modelled successfully [68].

\subsection{Uncertainty analysis and the bootstrap}

Experimental data are often accompanied by an error estimate and/or confidence interval, allowing the reader to assess the degree to which the given data may be "trusted". Although these ranges aren't always rigorously determined, even an estimate of the data uncertainty can be most useful when implemented in parameter estimation, model optimization and process design. Several journals now require the explicit reporting of experimental error, but the widespread application of uncertainty analysis for thermodynamic modelling and process design has yet to penetrate mainstream process industries [26].

Whiting and co-workers extensively studied the sensitivity of process design to experimental errors and propose ways to quantify and apply uncertainty analysis [77-80]. While this list of studies is not exhaustive, it provides a good sampling of the type of investigations completed. Several relevant topics were considered, such as the effect on parameterization using different data sets for the same components/mixtures and error propagation (both random and systematic) in process designs, with the Monte Carlo approach used as the main analysis tool. These methods are however relatively complex, meaning that implementation has not been widespread. As a counter to this, Mathias [26] proposed an intuitive perturbation method for activity coefficient models which could more easily be implemented by the average design engineer. This method is relatively simple, but requires the user to assess the accuracy of given data sets and then apply the perturbation. The sensitivity of various process variables (e.g. reboiler duty or final product specification) can then be calculated. These methods were expanded to equation of state models by Burger et al. [27]. 
Returning to statistically based methodology, Bjørner et al. [28] proposed parameterization via the bootstrapping methods first proposed by Bradley Efron in the 1970s [81]. Although it took some years for the popularization of the method (even within the statistical community), its use became much more prevalent from the mid-1980s onwards [82-84] with the 1986 article of Efron and Tibshirani now having more than 2850 citations. The implementation of Bjørner et al. [28] considered a bootstrap method referred to as resampling of residuals. Following an initial optimization, the residuals are randomly sampled (with replacement), summed with the model prediction, and then parameters are refitted to this pseudo data set. When repeated a sufficiently large amount of times, parameter distributions are determined. If the parameters are normally distributed, the bootstrapped result (mean parameter set) will be relatively close to the result of a standard nonlinear regression. This is however not always the case, with highly skewed and bimodal parameter distribution being possible. These distributions indicate the possibility of multiple solutions and a larger degree of uncertainty in the optimization result - all of which is impossible to know without implementing the bootstrap methodology. Once the parameter distributions are known, obtaining the desired confidence interval is trivial and the Monte Carlo simulations can be used to generate inputs for process designs. This method has an as yet untapped potential, whereby the process simulation package developer can perform all the calculations to determine the parameter distributions and then incorporate the confidence intervals into the design software. The user can simply specify a desired confidence interval for the equation of state or activity coefficient model and produce an estimated operating range rather than a single point. 


\section{Methodology}

New association schemes are proposed for mono-ethylene glycol, which make use of the binary association site. This follows similar thinking to that of de Villiers et al. [25] in the development of the $2 \mathrm{C}$ scheme 1-alkanols. Parameterization and evaluation of these schemes is done using a non-linear optimization algorithm, along with the bootstrap method for uncertainty analysis of the new parameter sets. While this work is only implemented for CPA, it could very naturally be extended to other SAFT-based equations of state.

\subsection{New association schemes for glycols}

MEG has traditionally been modelled using the $4 \mathrm{C}$ scheme after it was shown to be superior to the $2 \mathrm{~B}$ scheme.

The implementation of the bipolar site is shown in Figure 8, where three new schemes are proposed:

- 3C: the positive and negative sites on one side of the glycol are combined into 1 bipolar site

- $4 \mathrm{E}$ : the positive and negative sites on one side of the glycol are combined into 2 bipolar sites

- 4F: on each side of the glycol molecule, a negative site represents one of the lone electron pairs on the hydroxyl oxygen, while the $2^{\text {nd }}$ pair is combined with the hydrogen to form a bipolar site

Analytical site expressions can be developed for each association scheme, but these become very complex and are unnecessary for solving the association term in the modern formulations. The association dynamics for the three new schemes are compared to the $4 \mathrm{C}$-glycol $4 \mathrm{C}$-water configuration in Figure 9. For the traditional 4C-4C modelling approach, perfect symmetry is seen both within and between self- and crossassociation. This means that each association site has an equal chance of forming a bond and when it does bond, there is again an equal chance for a self- or cross-association bond. This is at odds with the molecular simulation results of Olsen et al. [55]. 
Each of the new schemes allows a greater proportion (ratio of green to orange) of self-association compared to the $4 \mathrm{C}$ approach (1:1 ratio), with ratios of cross-association also increasing. For the $3 \mathrm{C}$ and $4 \mathrm{E}$ schemes, the proportion of self-association to cross-association has increased (in agreement with the indications given by Olsen et al. [55]) while for the $4 \mathrm{~F}$ there is still an equal likelihood for self- and crossassociation. For the $3 \mathrm{C}$ scheme, there are also more cross-association configurations than self-association due to there being fewer association sites on the glycol, but this may be offset by having a maximum of three bonds per glycol.

\subsection{Optimization algorithm and data selection}

A weighted relative squared error function was used for parameterization of the new association schemes:

$$
O F_{\min }\left(a_{0}, b, c_{1}, \frac{\varepsilon}{R}, \beta, k_{i j}\right)=\sum w_{i} \sum\left|\frac{i_{c a l c}-i_{\text {exp }}}{i_{\text {exp }}}\right|^{2}
$$

The minimization was done with the Isqnonlin function in MATLAB ${ }^{\circledR}$ R2016a (Mathworks, 2016) using the Levenberg-Marquardt algorithm. The step and function tolerances were set to $10^{-9}$ and multiple random starts were implemented to avoid local minima issues as far as possible. In Eq. 8, i represents the various data included and $w$ is regression weight used in the optimization algorithm. Different weighting values were also tested and although the impact was relatively small, the following weighting was used:

$$
w_{i}=1-\frac{\text { data points of type } i}{\text { total data points }}
$$

Eq. 9

This weighting function will increase the weight of individual data points in smaller data sets (e.g. LLE), but overall optimization will still weigh more strongly for the larger data sets (specifically $\mathrm{P}_{\mathrm{Sat}}$ ). Data selection (see section 3.4) was found to have the largest impact, especially due to the inconsistencies seen for some 
data (especially TPx for MEG- $\mathrm{CH}_{4}$, as discussed in section 2.1.2) and the effect of using the DIPPR correlation on the bootstrap analysis (discussed later). Several different data types $\left(P_{\text {Sat }}, \rho, \Delta H_{V A P}, T P x, T P y\right.$, LLE) were tested, with the best results given by the inclusion of saturated vapour pressure and liquid density along with LLE data i.e. $i \in\left[P_{S a t}, \rho, L L E\right]$. The remaining data (TPx, TPy) was used for fitting new $\operatorname{BIPs}\left(\mathrm{k}_{\mathrm{ij}}\right)$ and evaluation purposes.

\subsection{Bootstrap methodology}

Although several bootstrap methods/variations exist, all of them revolve around the use of random sampling (with replacement) and repetition of a calculation (a statistically-significant number of times) in order to generate a distribution of the result of that calculation. Using the distribution, several statistical determinations can be made (e.g. mean, median, confidence interval etc.) and one can sample from the distribution as an input for a process input variable in error propagation studies. Given that the goal of the methodology is to calculate confidence intervals, which are very much related to the variance in the input data, the use of raw data over correlations would seem preferable.

We applied the bootstrap methodology in the following manner:

1. Pure component and binary data are chosen (see section 3.4) for parameter estimation

2. Finding the "optimum" parameters through minimization of Eq. 8 (all parameters optimized)

a. Multiple runs with perturbed initial parameters were used

b. Additional BIPs were optimized for TPx binary data (MEG-CH 4 and MEG- $\mathrm{H}_{2} \mathrm{O}$ ) not included in the data selection step (see section 3.4)

3. The "optimum" parameters were then bootstrapped

a. Random selection (with replacement) from the parameter estimation data (step 
b. Refitting the parameters using the "optimum" parameters as the initial guess

c. Optimize additional BIPs (this was done by fitting the liquid phase of the binary)

d. Record optimized parameters and repeat bootstrap 1500 times

e. If the mean value of the parameters found in the bootstrap process was significantly different from the original "optimum" parameters, the bootstrap was repeated using the mean parameter values

4. Using the distributions for each parameter in the parameter set, the covariance, correlation and confidence intervals (along with the accompanying co-parameter confidence ellipsoids) using the same method as Bjørner et al. [28]

An important step during the method development was determining a sufficient number of repetitions. This was done by doing three parallels of the bootstrap with $25,50,100,250,500,750,1000$ and 1500 repetitions each. It was found that for our optimization algorithm, the bootstrapped confidence intervals become constant to three or more significant figures between $500-750$ repetitions. Despite this finding, we decided to use 1500 repetitions as the additional calculation time ( $\sim 30$ minutes) was not deemed overly expensive.

\subsection{Data selection}

As discussed in the literature review, several previous studies have used the DIPPR correlations to generate pseudo pure component data (usually $\mathrm{P}_{\text {sat }}$ and $\rho$ ). When only parameter fitting is done, this can be quite useful (especially for the removal of weighting effects by the selection of equally spaced data points), but we found that using the DIPPR correlations (and especially when combined with resampling of residuals bootstrap) generated a significant amount of parameter correlation when evaluating the results of the uncertainty analysis. This is the result of what could be termed as correlating a correlation and for this reason we decided to use a selection of raw data rather than the DIPPR correlation. Generally, the raw 
experimental data is available for regions of interest (for dehydration and regeneration applications), but the reader should be aware of this when using these parameter sets at higher temperatures. Given the extrapolation done for the DIPPR correlations, the same caveat should probably apply to the standard literature parameter sets as well.

\subsubsection{MEG data used in optimization (parameter regression):}

Pure component vapour pressure [85-89] and density [90-93] data used for parameterization of MEG is shown in Figure 10. Relatively even data distributions were sought, which is more easily achieved for vapour pressure data than density. Newer sources were generally preferred and the DIPPR correlations were used as selection guidelines. Data points with a relative deviation of greater than $\pm 5 \%$ and $\pm 1 \%$ versus DIPPR were automatically excluded and the average relative deviations were calculated at $1.32 \%$ and $0.06 \%$ for saturated vapour pressure and liquid density respectively.

Binary LLE data (MEG- $n \mathrm{C}_{6} \& \mathrm{MEG}-n \mathrm{C}_{7}$ ) of Derawi et al. [41] were also included in the first optimization step. Following a preliminary investigation, the ECR combining rules were found to be preferable for all new association schemes which is in agreement with the literature for the $4 \mathrm{C}$ association scheme $[57,58]$. The choice of combining rule was found to be especially important for prediction of the MEG vapour phase content in MEG- $\mathrm{H}_{2} \mathrm{O}-\mathrm{CH}_{4}$ ternary system.

\subsubsection{MEG data used for BIP regression and evaluation:}

The following data were selected for use in sensitivity analysis, additional evaluation, and BIP regression:

- TPx MEG-CH 4 of Jou et al. [34] at 298 and $323 \mathrm{~K}$ (closest to range of application)

- TPy MEG-CH${ }_{4}$ of Miguens et al. [40] (all data) as well as the points [T,P] $\varepsilon[278,100 ; 278,200$; 298,200; 323,200] from Folas et al. [14] 
- MEG- $\mathrm{H}_{2} \mathrm{O}$ VLE of Kamihama et al. [88] (isobaric Tx at 1 bar) were used since they achieved the best results for thermodynamic consistency

Both phases for MEG- $\mathrm{H}_{2} \mathrm{O}$ are not included in BIP regression, but it is observed that the errors for both phases are comparable and generally rather small ( 5-10\%). The opposite was observed for MEG- $-\mathrm{CH}_{4}$, where improvement in the description of one phase would (in general) rather drastically decrease the performance for the other phase. Given that the MEG- $\mathrm{H}_{2} \mathrm{O}$ data were measured together in the same experimental apparatus, whereas no such combined two-phase MEG- $\mathrm{CH}_{4}$ data sets exist, this finding is not necessarily unexpected. It does however highlight the need for more complete MEG-CH ${ }_{4}$ VLE data sets. Such data would assist the quantification of model deficiencies and prove invaluable for the identification and evaluation of possible modelling improvements. 


\section{Results \& Discussion}

\subsection{Initial sensitivity analysis}

Initially a sensitivity analysis was done to identify whether improvements are possible and also where the problems with the existing parameter sets may lie. Each EoS parameter $\left(b, \Gamma, c_{1}, \varepsilon / R, \beta, k_{i j}\right)$ is varied in isolation, with the results presented in Figures 11-12.

The parameter sensitivity is compared to the pure component data selected in Section 3.4.1. It is seen that the b-parameter has the biggest influence on the density, while $\varepsilon / R$ and $\Gamma$ (or $a_{0}$ since $b$ is kept constant) have the greatest effect on the vapour pressure. Figure 11 indicates that a significant improvement for the density prediction may be possible if the b-parameter is decreased while simultaneously changing either $\varepsilon / R$ or $\Gamma$ to offset the effect on vapour pressure. The non-optimal description (for pure components) is partly due to evaluation against different input data (DIPPR data versus raw experimental), but even so, there remains clear room for improvement especially w.r.t. to the liquid density.

For Figure 12 the following data sets are used: $\mathrm{MEG}-\mathrm{CH}_{4}$ and $\mathrm{MEG}-\mathrm{H}_{2} \mathrm{O}$ as described in Section 3.4.2, and LLE data of Derawi et al. [41]. $\varepsilon / R$ is the most important parameter the binary data used in this analysis apart from the liquid phase of $\mathrm{MEG}-\mathrm{CH}_{4}$. It is noted that the BIPs have a much smaller relative effect and also that the effect is opposite for the liquid and vapour phases of $\mathrm{MEG}-\mathrm{CH}_{4}$ i.e. changing the $\mathrm{k}_{\mathrm{ij}}$ in a certain direction improves the description of one phase while worsening the description of the other. The effect of the inclusion of the LLE MEG $+n C_{7}$ data in the parameterization of the literature 4 C scheme is evident in the bottom right-hand graph in Figure 12.

\subsection{Optimization and uncertainty analysis}

As discussed in the Methodology (section 3.4), several different data types were used in the parameterization and evaluation procedures. For this reason, a form of radar plot was chosen to represent 
the results. In the radar plots, each data type is represented along one of eight axes. The absolute relative deviation is plotted radially outwards, with contour lines provided for ease of reading. Therefore, the further from the origin a point is located, the greater the fitting error for that data type. By connecting the points of each parameter set, a regular polygon is formed. By comparing the areas/relative sizes of the polygons, one can interpret the relative performance of various parameter sets. Data sets which were included in the optimization and bootstrapping are marked with an asterisk $(*)$ in the radar plots.

The results for the three new association schemes are shown in Figures 13-15 respectively along with the 95\% confidence interval calculated using the distribution of errors for the 1500 bootstrap steps. Figure 16 shows the results for the existing $4 \mathrm{C}$ scheme.

From the figures above and Table A 5 in Appendix A, a few general trends can be observed:

- The confidence intervals are smaller (in absolute terms) ${ }^{4}$ for data types which contain a larger number of points (i.e. density and vapour pressure), with the LLE results generally having the largest uncertainty

- Each of the new schemes (including the new $4 \mathrm{C}$ parameter set) offer improved description for MEG-related systems, at least for the systems investigated here

- No single association scheme offers a universally improved result

- The new $4 \mathrm{E}$ and $4 \mathrm{~F}$ schemes are virtually indistinguishable in terms of modelling accuracy

- The $4 C$ scheme with new parameters is still able to describe LLE while simultaneously providing mild improvement for the important MEG content in the gas phase

- The $3 C$ offers the best performance for pure component density and MEG in gas, but does not predict the MEG $+n C_{7}$ LLE very well

\footnotetext{
${ }^{4}$ Although in relative terms, only TPy $\left(\mathrm{MEG}-\mathrm{CH}_{4}\right)(7 \%)$ and LLE (MEG- $\left.n \mathrm{C}_{6}\right)(43 \%)$ do not fall within a $15-30 \%$ range as evaluated by: $\mathrm{Cl}_{\mathrm{REL}}=\left(\mathrm{Cl}_{\mathrm{ub}}-\mathrm{Ci}_{\mathrm{lb}}\right) / \mu_{\text {boot }}$
} 
The overall LLE results are somewhat contradictory, with the $4 \mathrm{C}$ scheme (old and new parameters) yielding errors of around $9 \%$ and $3 \%$ for the $n C_{6}$ and $n C_{7}$ systems respectively. The best results ( 4\%) for $n-C_{6}$ were achieved by the $4 \mathrm{E}$ and $4 \mathrm{~F}$ schemes. While it may be possible to further improve these results by tinkering with the regression weights, it seems unlikely that one parameter set will satisfy both data sets.

The biggest improvements were observed for MEG saturated density as well as the MEG- $\mathrm{H}_{2} \mathrm{O}$ binary. The MEG-3C density for instance, is shown to be 8 times better than the literature parameters $(0.29 \%$ versus 2.44\% AARD), while even the new $4 \mathrm{C}$ parameters (worst performing of the new parameter sets presented in this work) offer a 4 times better description ( $0.66 \%$ versus $2.44 \%$ AARD).

The parameter distributions and parameter co-variance plots from the bootstrap analysis are provided in the supplementary material. Although the distributions aren't always normal, none of the distributions exhibit obvious bimodal nature $e^{5}$ and in general the evaluated parameter value is at or near the mean/central value of the distribution. The closest cases for true bimodal behaviour are the b-parameter for the $4 \mathrm{C}, 4 \mathrm{E}$ and $4 \mathrm{~F}$ schemes, although it should be noted that the tails of this distribution are still quite far removed from the literature value of Derawi et al. [94]. By comparison, the b-distribution for the $3 \mathrm{C}$ scheme was very near to a normal distribution.

The BIPs exhibit a false bimodal behaviour due to sharp peaks resulting from the optimizer exiting the algorithm without changing the BIP value. This occurs as the BIPs do not influence the overall result as strongly as the other parameters and could be remedied by setting smaller tolerances for the optimizer, but would not drastically change the final result. This effect was most visible for the $\mathrm{MEG}+\mathrm{CH}_{4}$ and MEG $+\mathrm{H}_{2} \mathrm{O}$ BIPs.

In general, the parameter distributions of $3 \mathrm{C}$ scheme exhibited the most normal behaviour. The 4-site schemes generally exhibited positively skewed distributions for SRK parameters $b, a_{0}$ and $c_{1}$, while the association parameters $(\varepsilon / R$ and $\beta)$ were negatively skewed. Figures $17(3 C)$ and $18(4 C)$ are representative

\footnotetext{
${ }^{5}$ Bimodal behaviour indicates a high probability of two "optimal" parameter values
} 
of these differences, with the all the distributions available in the Supplementary Material. Although it is difficult to draw clear conclusions from this result w.r.t. the relative performance of the 3-site versus 4-sites schemes, it is nonetheless a distinct and interesting difference.

For the parameter distributions and co-variance plots we chose to examine $a_{0}$ rather than $\Gamma$, in order to decouple the effects of $b$ in $\Gamma$. For the co-variance plots it is noticeable that there is significantly less correlation than seen for the methods used by Bjørner et al. [28]. The clearest case of correlation is shown for $\varepsilon / R$ with $a_{0}$.

\subsection{Analysis and application}

Single parameter sensitivity analysis was also done for the new association schemes and parameter sets.

Figures 19 and 20 show the sensitivity analysis for the new $3 \mathrm{C}$ association scheme and are representative of the sensitivity analyses for the 4-site schemes (provided in the Supplementary Material). Naturally the pure component and LLE data achieve favourable results (meaning most of the parameters being at or near their optimal values) as they were included in the optimization and bootstrapping process. However, other data sets such as the MEG-CH and MEG- $\mathrm{H}_{2} \mathrm{O}$ (liquid) binaries are also near optimal, despite not having been included in the optimization (apart from regressing BIPs for the new parameter sets). Discrepancies are observed in the MEG- $\mathrm{H}_{2} \mathrm{O}$ vapour phase modelling for all cases considered in this work. These discrepancies could be due to thermodynamic inconsistency in the data or a model deficiency, but the exact cause is difficult to pinpoint. Covariance plots for the BIPs were examined, but no clear conclusions could be drawn. However, the improvements over the literature parameters serve to highlight the power of uncertainty analysis and the bootstrapping technique for the parameterization of equations of state. 
The new association schemes and parameter sets were also evaluated against newly published density data from Crespo et al. [33] which extend to pressures up to 950 bar. The results are shown in Table 2, with figures for each isotherm available in the Supplementary Materials.

In Table 2, \%ARD (rather than \%AARD) is shown in order to highlight the directionality of the errors. Each of the new association schemes and parameter sets provide a significant improvement over the literature $4 \mathrm{C}$ parameter set, which chronically underpredicts the density data. Although the $3 C$ scheme performs the best overall, the new $4 \mathrm{C}$ parameter set performs better at temperatures less than $323 \mathrm{~K}$. However, evaluation of the graphs reveals that the new schemes (3C, 4E and 4F) are better for pressures below 200 bar. None of the models perfectly capture the curvature of the data, but significant improvements over the literature paramaters are atttained.

In general, we can say that the overall results (i.e. \%AARD in Table 2) are very similar to those for the saturated density data used in the parameter estimation, both in terms or relative order (4C-Lit $>>4 C>4 E / 4 F>3 C$ ) and magnitude. This would suggest a degree of equivalence between the saturated density and these data, at least for parameter estimation purposes. This hypothesis was briefly tested by repeating the bootstrap algorithm and optimization by using the data of Crespo et al. [33] instead of the saturated density data. The optimal parameter sets were found to be very similar to those determined using saturated density data.

In terms of the application for our work, the modelling of MEG in gas phase in mixtures with water, methane and other natural gas components is crucial. From the available literature data, the new asssocation schemes and parameter sets can be evaluated against $\mathrm{MEG}-\mathrm{CH}_{4}$ data of Miguens et al. [40] and the ternary MEG- $\mathrm{H}_{2} \mathrm{O}-\mathrm{CH}_{4}$ data of Folas et al. [14].

In Figure 21, the pure predictive (no BIPs) ability of various schemes are compared and interestingly the literature $4 \mathrm{C}$ parameters, $4 \mathrm{E}$ and $4 \mathrm{~F}$ schemes produce very similar predictions for MEG in the gas phase. 
The experimental data is overpredicted, with the new $4 \mathrm{C}$ parameter set providing the best results. Fitting MEG-CH${ }_{4}$ BIPs (values shown in the first line of Table 3) to the data of Miguens et al. [40] yields in almost identical curves with an overall fitting error of $\sim 7 \%$. The new $4 \mathrm{C}$ parameter set yields the smallest BIP while the new $3 \mathrm{C}$ association schemes yields the largest.

For evaluating the model performance for $\mathrm{MEG}-\mathrm{H}_{2} \mathrm{O}-\mathrm{CH}_{4}$ systems, only the data of Folas et al. [14] provide both phases. The data are evaluated for in three ways: using no BIPs, using BIPs fitted to TPx data during the parameter estimation and bootstrapping (values shown in Tables A1-A4 in Appendix A), and using BIPs fitted to TPy data (values shown in Table 3). Where applicable, the value of -0.045 is used for the BIP of $\mathrm{H} 2 \mathrm{O}-\mathrm{CH} 4$. The results of this evaluations are summarized in Table 4 with selected graphical results in Figures 22 and 23, and the full graphical results provided in the Supplementary Material.

The following observations are made for the modelling of the ternary data:

- Without using BIPs:

The $4 \mathrm{E}$ and $4 \mathrm{~F}$ schemes provide the best predictive results for both phases

- All data points are overpredicted by the models

- When using BIPs fitted to liquid phase VLE:

- The $3 \mathrm{C}$ and $4 \mathrm{C}$ schemes offer better results for $\mathrm{H}_{2} \mathrm{O}$ in gas $\left(\mathrm{y}_{2}\right)$

- The $4 \mathrm{E}$ and $4 \mathrm{~F}$ schemes provide better results for $\mathrm{MEG}$ in gas $\left(\mathrm{y}_{1}\right)$ and $\mathrm{CH}_{4}$ in liquid $\left(\mathrm{x}_{3}\right)$

- When using BIPs fitted to vapour phase VLE:

- The results are universally better (even for the ternary liquid phase) compared to those using BIPs fitted to the various binary liquid phase data

- For the $\mathrm{CH}_{4}$ solubility in the liquid phase $\left(\mathrm{x}_{3}\right)$ :

- None of the schemes capture the temperature dependency using only a single BIP

- For MEG $\left(\mathrm{y}_{1}\right)$ and $\mathrm{H}_{2} \mathrm{O}\left(\mathrm{y}_{2}\right)$ in gas: 
- The $3 \mathrm{C}$ and new $4 \mathrm{C}$ parameters offer only a slightly difference from the literature $4 \mathrm{C}$ parameters

- The models capture the temperature dependency much better than for $\mathrm{x}_{3}$

- If the average of the three errors are calculated, the $4 \mathrm{~F}$ scheme always achieves lowest average error

- With respect to the data, the curvature of the MEG in gas $\left(\mathrm{y}_{2}\right)$ data at $278 \mathrm{~K}$ and $298 \mathrm{~K}$ (around 100 bar) seems inconsistent, with all the models more closely resembling the $278 \mathrm{~K}$ data trend

Given the results for modelling of the ternary data, the $4 \mathrm{~F}$ scheme would appear to be the best for modelling MEG in natural gas dehydration applications and that better predictive modelling is achieved when BIPs are fitted to vapour phase binary VLE data. It is stressed that these conclusions are based on evaluations against very small data sets and this should be kept in mind by the user. Similar evaluations were performed for the binary $\mathrm{MEG}-\mathrm{CH}_{4}$ data by fitting a BIP to one phase and then evaluating the performance for predicting the other. Simultaneous description of both phases could not be achieved with the use of a single BIP and generally resulted in poor prediction for the non-fitted data.

\section{Conclusions and Future Work}

Three new association schemes ( $3 \mathrm{C}, 4 \mathrm{E}$ and $4 \mathrm{~F}$ ) have been proposed for MEG for the improved thermodynamic modelling of systems related to natural gas dehydration. These association schemes each utilized the binary association site first used for acids ( $1 \mathrm{~A}$ scheme) and later for alcohols ( $2 \mathrm{C}$ scheme). For MEG- $\mathrm{H}_{2} \mathrm{O}$ mixtures, these new schemes introduce an asymmetry into the association ensemble which is more in line with new molecular simulation results for glycol-water systems.

Single parameter sensitivity analysis of the literature CPA-4C set identified that improved modelling descriptions were also possible and to this end the bootstrapping technique has been applied to generate four bounded parameter sets for the $3 \mathrm{C}, 4 \mathrm{C}, 4 \mathrm{E}$ and $4 \mathrm{~F}$ association schemes for MEG. A combination of 
pure component saturated vapour pressure and liquid density, and binary LLE data were incorporated into the optimization and bootstrapping algorithms. Each of the new parameter sets showed significantly improved results in the description of MEG saturated density and vapour pressure, as well as VLE for MEG$\mathrm{H}_{2} \mathrm{O}$ and MEG- $\mathrm{CH}_{4}$ which were not included in the optimization algorithms. The results for description for MEG-hydrocarbon LLE were slightly contradictory as the $4 C$ scheme performed the best for $n C_{7}$, while the $4 \mathrm{E}$ and $4 \mathrm{~F}$ schemes were best for $n \mathrm{C}_{6}$. Meanwhile the $3 \mathrm{C}$ scheme provided the best results for pure component properties and liquid phase MEG- $\mathrm{H}_{2} \mathrm{O}$. No single scheme or parameter set was found to be universally the best. Single parameter sensitivity analysis was also applied to the four new parameter sets, indicating that only incremental improvements are still likely.

A review of the uncertainty analysis (distributions of the data set errors, parameter distributions and covariance plots) revealed that:

- the available LLE data carries the most uncertainty

- the 3 C scheme has normal parameter distributions

- the 4-site schemes have skewed parameter distributions with hints of bimodal behaviour which may indicate dual optimal solutions in the area of investigation

- very few parameters display correlation, likely due to the use of raw experimental data and the simplified bootstrap

For the most important application of this work (the prediction of $\mathrm{H}_{2} \mathrm{O}$ and MEG in the gas phase of mixtures with natural gas components), the $4 \mathrm{~F}$ scheme (combined with BIPs fitted to the vapour phase of binary data) provides the best overall results for the single available set of ternary data.

Analysis of the literature data already indicated a serious need for thermodynamically consistent MEG- $\mathrm{CH}_{4}$ data to be produced and this, along with the need for more MEG-hydrocarbon LLE data, has been 
highlighted by the uncertainty analysis. It was shown that uncertainty ranges increase when few data are available and also when the available data are inconsistent. One area for future consideration would be the BIP regression e.g. how can we improve the description of both phases for $\mathrm{MEG}-\mathrm{CH}_{4}$ using a single BIP? Is this a data problem or a model problem? As part of the resolution to data availability issue we are in the process of measuring new data binary, ternary and multicomponent for various glycol-water-hydrocarbon systems.

Although this work has focussed on narrow applications and data ranges, the methods used here can be extended as and when additional data becomes available. The beauty of the bootstrap method applied to chemical process design, is that it allows one to transfer uncertainty from experimental data into thermodynamic models, and later into process models and designs. Rigorous and robust implementation of this method for all compounds is impractical, but could we in the future see the same requirements of modelers to provide well-defined parameter uncertainty ranges in the same way that experimentalists are being required to provide the experimental uncertainty? 


\section{References}

[1] T.V. Løkken, Water vapour measurements in natural gas in the presence of ethylene glycol, J. Nat. Gas Sci. Eng. 12 (2013) 13-21. doi:10.1016/j.jngse.2013.01.002.

[2] A.L. Kohl, R.B. Nielsen, Chapter 11 - Absorption of Water Vapor by Dehydrating Solutions, in: Gas Purif. Fifth Ed., Gulf Professional Publishing, Houston, 1997: pp. 946-1021. doi:10.1016/B978088415220-0/50011-2.

[3] D.A. Eimer, Gas Dehydration, in: Gas Treat., John Wiley \& Sons, Ltd, 2014: pp. 267-281. doi:10.1002/9781118877746.ch14.

[4] M. Neagu, D.L. Cursaru, Technical and economic evaluations of the triethylene glycol regeneration processes in natural gas dehydration plants, J. Nat. Gas Sci. Eng. 37 (2017) 327-340. doi:10.1016/j.jngse.2016.11.052.

[5] C.A. Scholes, G.W. Stevens, S.E. Kentish, Membrane gas separation applications in natural gas processing, Fuel. 96 (2012) 15-28. doi:10.1016/j.fuel.2011.12.074.

[6] C. Wen, X. Cao, Y. Yang, Swirling flow of natural gas in supersonic separators, Chem. Eng. Process. Process Intensif. 50 (2011) 644-649. doi:10.1016/j.cep.2011.03.008.

[7] K. Dalane, Z. Dai, G. Mogseth, M. Hillestad, L. Deng, Potential applications of membrane separation for subsea natural gas processing: A review, J. Nat. Gas Sci. Eng. 39 (2017) 101-117. doi:10.1016/j.jngse.2017.01.023.

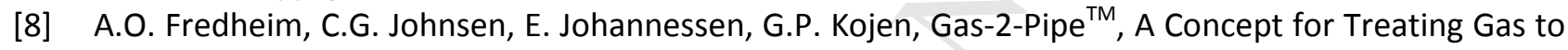
Rich Gas Quality in a Subsea or Unmanned Facility, in: Offshore Technology Conference, 2016. doi:10.4043/27147-MS.

[9] TERMS AND CONDITIONS FOR TRANSPORTATION OF GAS IN GASSLED, (n.d.). http://www.gassco.no/contentassets/40e7d932034346caaa7ac647bcd9ee6f/terms-and-conditions01.07.2017---incl.-appendix.pdf (accessed August 6, 2017).

[10] G.K. Folas, G.M. Kontogeorgis, M.L. Michelsen, E.H. Stenby, Application of the Cubic-Plus-Association (CPA) Equation of State to Complex Mixtures with Aromatic Hydrocarbons, Ind. Eng. Chem. Res. 45 (2006) 1527-1538. doi:10.1021/ie050976q.

[11] E. Hendriks, G.M. Kontogeorgis, R. Dohrn, J.-C. de Hemptinne, I.G. Economou, L.F. Žilnik, V. Vesovic, Industrial Requirements for Thermodynamics and Transport Properties, Ind. Eng. Chem. Res. 49 (2010) 11131-11141. doi:10.1021/ie101231b.

[12] X. Liang, G. Aloupis, G.M. Kontogeorgis, Data Requirements and Modeling for Gas Hydrate-Related Mixtures and a Comparison of Two Association Models, J. Chem. Eng. Data. (2017). doi:10.1021/acs.jced.7b00081.

[13] E. Petropoulou, G.D. Pappa, E. Voutsas, Modelling of phase equilibrium of natural gas mixtures containing associating compounds, Fluid Phase Equilibria. 433 (2017) 135-148. doi:10.1016/j.fluid.2016.10.028.

[14] G.K. Folas, O.J. Berg, E. Solbraa, A.O. Fredheim, G.M. Kontogeorgis, M.L. Michelsen, E.H. Stenby, Highpressure vapor-liquid equilibria of systems containing ethylene glycol, water and methane: Experimental measurements and modeling, Fluid Phase Equilibria. 251 (2007) 52-58. doi:10.1016/j.fluid.2006.11.001.

[15] G.M. Kontogeorgis, E.C. Voutsas, I.V. Yakoumis, D.P. Tassios, An Equation of State for Associating Fluids, Ind. Eng. Chem. Res. 35 (1996) 4310-4318. doi:10.1021/ie9600203.

[16] G.M. Kontogeorgis, I. V. Yakoumis, H. Meijer, E. Hendriks, T. Moorwood, Multicomponent phase equilibrium calculations for water-methanol-alkane mixtures, Fluid Phase Equilibria. 158-160 (1999) 201-209. doi:10.1016/S0378-3812(99)00060-6.

[17] G. Soave, Equilibrium constants from a modified Redlich-Kwong equation of state, Chem. Eng. Sci. 27 (1972) 1197-1203. doi:10.1016/0009-2509(72)80096-4. 
[18] M.S. Wertheim, Fluids with highly directional attractive forces. I. Statistical thermodynamics, J. Stat. Phys. 35 (1984) 19-34. doi:10.1007/BF01017362.

[19] M.S. Wertheim, Fluids with highly directional attractive forces. II. Thermodynamic perturbation theory and integral equations, J. Stat. Phys. 35 (1984) 35-47. doi:10.1007/BF01017363.

[20] M.S. Wertheim, Fluids with highly directional attractive forces. III. Multiple attraction sites, J. Stat. Phys. 42 (1986) 459-476. doi:10.1007/BF01127721.

[21] M.S. Wertheim, Fluids with highly directional attractive forces. IV. Equilibrium polymerization, J. Stat. Phys. 42 (1986) 477-492. doi:10.1007/BF01127722.

[22] W.G. Chapman, K.E. Gubbins, G. Jackson, M. Radosz, SAFT: Equation-of-state solution model for associating fluids, Fluid Phase Equilibria. 52 (1989) 31-38. doi:10.1016/0378-3812(89)80308-5.

[23] W.G. Chapman, K.E. Gubbins, G. Jackson, M. Radosz, New reference equation of state for associating liquids, Ind. Eng. Chem. Res. 29 (1990) 1709-1721. doi:10.1021/ie00104a021.

[24] M.P. Breil, G.M. Kontogeorgis, Thermodynamics of Triethylene Glycol and Tetraethylene Glycol Containing Systems Described by the Cubic-Plus-Association Equation of State, Ind. Eng. Chem. Res. 48 (2009) 5472-5480. doi:10.1021/ie801412y.

[25] A.J. De Villiers, C.E. Schwarz, A.J. Burger, New association scheme for 1-alcohols in alcohol/water mixtures with sPC-SAFT: The 2C association scheme, Ind. Eng. Chem. Res. 50 (2011) 8711-8725. doi:10.1021/ie200521k.

[26] P.M. Mathias, Sensitivity of Process Design to Phase Equilibrium-A New Perturbation Method Based Upon the Margules Equation, J. Chem. Eng. Data. 59 (2014) 1006-1015. doi:10.1021/je400748p.

[27] J. Burger, N. Asprion, S. Blagov, M. Bortz, Simple Perturbation Scheme to Consider Uncertainty in Equations of State for the Use in Process Simulation, J. Chem. Eng. Data. 62 (2017) 268-274. doi:10.1021/acs.jced.6b00633.

[28] M.G. Bjørner, G. Sin, G.M. Kontogeorgis, Uncertainty analysis of the CPA and a quadrupolar CPA equation of state - With emphasis on CO2, Fluid Phase Equilibria. 414 (2016) 29-47. doi:10.1016/j.fluid.2015.12.037.

[29] B.H. Rusten, L.H. Gjertsen, E. Solbraa, T. Kirkerød, T. Haugum, S. Puntervold, Determination of the phase envelope - crucial for process design and problem solving, in: Annu. Conv. Gas Process. Assoc. 87, 2008: pp. 17-45.

[30] S.O. Derawi, M.L. Michelsen, G.M. Kontogeorgis, E.H. Stenby, Application of the CPA equation of state to glycol/hydrocarbons liquid-liquid equilibria, Fluid Phase Equilibria. 209 (2003) 163-184. doi:10.1016/S0378-3812(03)00056-6.

[31] L.C. dos Santos, S.S. Abunahman, F.W. Tavares, V.R. Ruiz Ahón, G.M. Kontogeorgis, Cubic Plus Association Equation of State for Flow Assurance Projects, Ind. Eng. Chem. Res. 54 (2015) 6812-6824. doi:10.1021/acs.iecr.5b01410.

[32] G.K. Folas, G.M. Kontogeorgis, M.L. Michelsen, E.H. Stenby, E. Solbraa, Liquid-Liquid Equilibria for Binary and Ternary Systems Containing Glycols, Aromatic Hydrocarbons, and Water: Experimental Measurements and Modeling with the CPA EoS, J. Chem. Eng. Data. 51 (2006) 977-983. doi:10.1021/je050485c.

[33] E.A. Crespo, J.M.L. Costa, Z.B.M.A. Hanafiah, K.A. Kurnia, M.B. Oliveira, F. Llovell, L.F. Vega, P.J. Carvalho, J.A.P. Coutinho, New measurements and modeling of high pressure thermodynamic properties of glycols, Fluid Phase Equilibria. 436 (2017) 113-123. doi:10.1016/j.fluid.2017.01.003.

[34] F.Y. Jou, F.D. Otto, A.E. Mather, Solubility of methane in glycols at elevated pressures, Can. J. Chem. Eng. 72 (1994) 130-133.

[35] D.-Q. Zheng, W.-D. Ma, R. Wei, T.-M. Guo, Solubility study of methane, carbon dioxide and nitrogen in ethylene glycol at elevated temperatures and pressures, Fluid Phase Equilibria. 155 (1999) 277-286. doi:10.1016/S0378-3812(98)00469-5.

[36] L.-K. Wang, G.-J. Chen, G.-H. Han, X.-Q. Guo, T.-M. Guo, Experimental study on the solubility of natural gas components in water with or without hydrate inhibitor, Fluid Phase Equilibria. 207 (2003) 143154. doi:10.1016/S0378-3812(03)00009-8. 
[37] M.A. Abdi, A. Hussain, K. Hawboldt, E. Beronich, Experimental study of solubility of natural gas components in aqueous solutions of ethylene glycol at low-temperature and high-pressure conditions, J. Chem. Eng. Data. 52 (2007) 1741-1746. doi:10.1021/je700134r.

[38] A.C. Galvão, A.Z. Francesconi, Solubility of methane and carbon dioxide in ethylene glycol at pressures up to $14 \mathrm{MPa}$ and temperatures ranging from (303 to 423) K, J. Chem. Thermodyn. 42 (2010) 684688. doi:10.1016/j.jct.2009.12.009.

[39] A. Bersås, Vapour-liquid equilibrium in the monoethylene glycol - methane system at elevated pressures, Norwegian University of Science and Technology, 2012. https://brage.bibsys.no/xmlui/handle/11250/2351862 (accessed July 17, 2017).

[40] A.C.M. Miguens, E. Solbraa, A.B. Hansen, T.V. Løkken, T. Haugum, S. Solvang, Glycols in natural gas Experiments, modelling and tracking, in: 2014: pp. 251-255.

[41] S.O. Derawi, G.M. Kontogeorgis, E.H. Stenby, T. Haugum, A.O. Fredheim, Liquid-Liquid Equilibria for Glycols + Hydrocarbons: Data and Correlation, J. Chem. Eng. Data. 47 (2002) 169-173. doi:10.1021/je010199a.

[42] A. Razzouk, R.A. Naccoul, I. Mokbel, P. Duchet-Suchaux, J. Jose, E. Rauzy, C. Berro, Liquid-Liquid Equilibria for Monoethylene Glycol + Hexane and 2,2,4-Trimethylpentane, Water + Hexane and 2,2,4Trimethylpentane, Monoethylene Glycol + Water + Hexane, and Monoethylene Glycol + Water + 2,2,4-Trimethylpentane in the Temperature Range between $\mathrm{T}=283.15 \mathrm{~K}$ and $\mathrm{T}=323.15 \mathrm{~K}$, J. Chem. Eng. Data. 55 (2010) 1468-1472. doi:10.1021/je900295u.

[43] I. Mokbel, C. Lindemann, P. Duchet-Suchaux, J. Jose, Liquid-liquid equilibria of binary and ternary systems involving monoethyleneglycol, water, $n$-alkanes at three temperatures: $283.15,303.15$ and 333.15K, Fuel. 163 (2016) 17-24. doi:10.1016/j.fuel.2015.09.037.

[44] F.-Y. Jou, K.A.G. Schmidt, A.E. Mather, Vapor-liquid equilibrium in the system ethane+ethylene glycol, Fluid Phase Equilibria. 240 (2006) 220-223. doi:10.1016/j.fluid.2005.12.032.

[45] F.-Y. JOU, R.D. DESHMUKH, F.D. OTTO, A.E. MATHER, Vapor-Liquid Equilibria of H2s and $\mathrm{CO2}$ and Ethylene Glycol at Elevated Pressures, Chem. Eng. Commun. 87 (1990) 223-231. doi:10.1080/00986449008940694.

[46] X. Gui, Z. Tang, W. Fei, Solubility of $\mathrm{CO} 2$ in alcohols, glycols, ethers, and ketones at high pressures from (288.15 to 318.15) K, J. Chem. Eng. Data. 56 (2011) 2420-2429. doi:10.1021/je101344v.

[47] C.-Y. Jiang, Z.-J. Sun, Q.-M. Pan, J.-B. Pi, Solubility of ethylene glycol in supercritical carbon dioxide at pressures up to $19.0 \mathrm{MPa}$, J. Chem. Eng. Data. 57 (2012) 1794-1802. doi:10.1021/je3002249.

[48] F.S. Serpa, R.S. Vidal, J.H.B.A. Filho, J.F. do Nascimento, J.R.P. Ciambelli, C.M.S. Figueiredo, G.R. Salazar-Banda, A.F. Santos, M. Fortuny, E. Franceschi, C. Dariva, Solubility of Carbon Dioxide in Ethane-1,2-diol-Water Mixtures, J. Chem. Eng. Data. 58 (2013) 3464-3469. doi:10.1021/je400736w.

[49] M. Riaz, G.M. Kontogeorgis, E.H. Stenby, W. Yan, T. Haugum, K.O. Christensen, E. Solbraa, T.V. Løkken, Mutual solubility of MEG, water and reservoir fluid: Experimental measurements and modeling using the CPA equation of state, Fluid Phase Equilibria. 300 (2011) 172-181. doi:10.1016/j.fluid.2010.10.006.

[50] M. Riaz, M.A. Yussuf, G.M. Kontogeorgis, E.H. Stenby, W. Yan, E. Solbraa, Distribution of MEG and methanol in well-defined hydrocarbon and water systems: Experimental measurement and modeling using the CPA EOS, Fluid Phase Equilibria. 337 (2013) 298-310. doi:10.1016/j.fluid.2012.09.009.

[51] M. Frost, G.M. Kontogeorgis, E.H. Stenby, M.A. Yussuf, T. Haugum, K.O. Christensen, E. Solbraa, T.V. Løkken, Liquid-liquid equilibria for reservoir fluids + monoethylene glycol and reservoir fluids + monoethylene glycol + water: Experimental measurements and modeling using the CPA EoS, Fluid Phase Equilibria. 340 (2013) 1-6. doi:10.1016/j.fluid.2012.11.028.

[52] M. Frost, G.M. Kontogeorgis, N. von Solms, T. Haugum, E. Solbraa, Phase equilibrium of North Sea oils with polar chemicals: Experiments and CPA modeling, Fluid Phase Equilibria. (n.d.). doi:10.1016/j.fluid.2015.11.030.

[53] S.H. Huang, M. Radosz, Equation of state for small, large, polydisperse, and associating molecules, Ind. Eng. Chem. Res. 29 (1990) 2284-2294. 
[54] G.M. Kontogeorgis, G.K. Folas, Association Theories and Models: The Role of Spectroscopy, in: Thermodyn. Models Ind. Appl., John Wiley \& Sons, Ltd, 2010: pp. 195-219. doi:10.1002/9780470747537.ch7.

[55] R. Olsen, B. Kvamme, T. Kuznetsova, Hydrogen bond lifetimes and statistics of aqueous mono-, di- and tri-ethylene glycol, AIChE J. 63 (2017) 1674-1689. doi:10.1002/aic.15539.

[56] A.K. Soper, F. Bruni, M.A. Ricci, Site-site pair correlation functions of water from 25 to $400{ }^{\circ} \mathrm{C}$ : Revised analysis of new and old diffraction data, J. Chem. Phys. 106 (1997) 247-254. doi:10.1063/1.473030.

[57] G.M. Kontogeorgis, G.K. Folas, Chapter 9: The Cubic-Plus-Association Equation of State, in: Thermodyn. Models Ind. Appl., John Wiley \& Sons, Ltd, 2010: pp. 261-297. http://onlinelibrary.wiley.com/doi/10.1002/9780470747537.ch9/summary (accessed May 25, 2016).

[58] G.M. Kontogeorgis, G.K. Folas, N. Muro-Suñé, S. von, M.L. Michelsen, E.H. Stenby, Modelling of associating mixtures for applications in the oil \& gas and chemical industries, Fluid Phase Equilibria. 261 (2007) 205-211. doi:10.1016/j.fluid.2007.05.022.

[59] G.M. Kontogeorgis, I. Tsivintzelis, N. von Solms, A. Grenner, D. Bøgh, M. Frost, A. Knage-Rasmussen, I.G. Economou, Use of monomer fraction data in the parametrization of association theories, Fluid Phase Equilibria. 296 (2010) 219-229. doi:10.1016/j.fluid.2010.05.028.

[60] I. Tsivintzelis, D. Bøgh, E. Karakatsani, G.M. Kontogeorgis, The role of monomer fraction data in association theories-Can we improve the performance for phase equilibrium calculations?, Fluid Phase Equilibria. 365 (2014) 112-122. doi:10.1016/j.fluid.2013.12.013.

[61] G.M. Kontogeorgis, Association theories for complex thermodynamics, Chem. Eng. Res. Des. 91 (2013) 1840-1858. doi:10.1016/j.cherd.2013.07.006.

[62] Brigham Young University (BYU), DIADEM Professional - DIPPR Information and Data Evaluation Manager, 2016.

[63] G.M. Kontogeorgis, G.K. Folas, Chapter 10: Applications of CPA to the Oil and Gas Industry, in: Thermodyn. Models Ind. Appl., John Wiley \& Sons, Ltd, 2010: pp. 299-331. http://onlinelibrary.wiley.com/doi/10.1002/9780470747537.ch10/summary (accessed May 25, 2016).

[64] G.M. Kontogeorgis, M.L. Michelsen, G.K. Folas, S. Derawi, N. von Solms, E.H. Stenby, Ten Years with the CPA (Cubic-Plus-Association) Equation of State. Part 1. Pure Compounds and Self-Associating Systems, Ind. Eng. Chem. Res. 45 (2006) 4855-4868. doi:10.1021/ie051305v.

[65] G.M. Kontogeorgis, M.L. Michelsen, G.K. Folas, S. Derawi, N. von Solms, E.H. Stenby, Ten Years with the CPA (Cubic-Plus-Association) Equation of State. Part 2. Cross-Associating and Multicomponent Systems, Ind. Eng. Chem. Res. 45 (2006) 4869-4878. doi:10.1021/ie051306n.

[66] H. Haghighi, A. Chapoy, R. Burgess, B. Tohidi, Experimental and thermodynamic modelling of systems containing water and ethylene glycol: Application to flow assurance and gas processing, Fluid Phase Equilibria. 276 (2009) 24-30. doi:10.1016/j.fluid.2008.10.006.

[67] S. Mazloum, A. Chapoy, J. Yang, B. Tohidi, A NOVEL TECHNIQUE FOR MONITORING HYDRATE SAFETY MARGIN, in: 2011. https://www.researchgate.net/publication/306039066_A_NOVEL_TECHNIQUE_FOR_MONITORING_H YDRATE_SAFETY_MARGIN (accessed July 18, 2017).

[68] F. Tzirakis, E. Karakatsani, G.M. Kontogeorgis, Evaluation of the Cubic-Plus-Association Equation of State for Ternary, Quaternary, and Multicomponent Systems in the Presence of Monoethylene Glycol, Ind. Eng. Chem. Res. 55 (2016) 11371-11382. doi:10.1021/acs.iecr.6b02642.

[69] G.K. Folas, E.W. Froyna, J. Lovland, G.M. Kontogeorgis, E. Solbraa, Data and prediction of water content of high pressure nitrogen, methane and natural gas, Fluid Phase Equilibria. 252 (2007) 162174. doi:10.1016/j.fluid.2006.12.018.

[70] W. Afzal, M.P. Breil, P. Théveneau, A.H. Mohammadi, G.M. Kontogeorgis, D. Richon, Phase Equilibria of Mixtures Containing Glycol and n-Alkane: Experimental Study of Infinite Dilution Activity Coefficients and Modeling Using the Cubic-Plus-Association Equation of State, Ind. Eng. Chem. Res. 48 (2009) 11202-11210. doi:10.1021/ie900856q. 
[71] I. Tsivintzelis, G.M. Kontogeorgis, M.L. Michelsen, E.H. Stenby, Modeling phase equilibria for acid gas mixtures using the CPA equation of state. I. Mixtures with H2S, AIChE J. 56 (2010) 2965-2982. doi:10.1002/aic.12207.

[72] I. Tsivintzelis, G.M. Kontogeorgis, M.L. Michelsen, E.H. Stenby, Modeling phase equilibria for acid gas mixtures using the CPA equation of state. Part II: Binary mixtures with CO2, Fluid Phase Equilibria. 306 (2011) 38-56. doi:10.1016/j.fluid.2011.02.006.

[73] I. Tsivintzelis, S. Ali, G.M. Kontogeorgis, Modeling Phase Equilibria for Acid Gas Mixtures using the Cubic-Plus-Association Equation of State. 3. Applications Relevant to Liquid or Supercritical CO2 Transport, J. Chem. Eng. Data. 59 (2014) 2955-2972. doi:10.1021/je500090q.

[74] I. Tsivintzelis, S. Ali, G.M. Kontogeorgis, Modeling phase equilibria for acid gas mixtures using the CPA equation of state. Part IV. Applications to mixtures of $\mathrm{CO} 2$ with alkanes, Fluid Phase Equilibria. 397 (2015) 1-17. doi:10.1016/j.fluid.2015.03.034.

[75] I. Tsivintzelis, G.M. Kontogeorgis, Modelling phase equilibria for acid gas mixtures using the CPA equation of state. Part V: Multicomponent mixtures containing $\mathrm{CO} 2$ and alcohols, J. Supercrit. Fluids. 104 (2015) 29-39. doi:10.1016/j.supflu.2015.05.015.

[76] I. Tsivintzelis, G.M. Kontogeorgis, Modelling phase equilibria for acid gas mixtures using the CPA equation of state. Part VI. Multicomponent mixtures with glycols relevant to oil and gas and to liquid or supercritical CO2 transport applications, J. Chem. Thermodyn. 93 (2016) 305-319. doi:10.1016/j.jct.2015.07.003.

[77] W.B. Whiting, T.M. Tong, M.E. Reed, Effect of uncertainties in thermodynamic data and model parameters on calculated process performance, Ind. Eng. Chem. Res. 32 (1993) 1367-1371. doi:10.1021/ie00019a011.

[78] M.E. REED, W.B. WHITING, Sensitivity and Uncertainty of Process Designs to Thermodynamic Model Parameters: A Monte Carlo Approach, Chem. Eng. Commun. 124 (1993) 39-48. doi:10.1080/00986449308936176.

[79] V.R. Vasquez, W.B. Whiting, Uncertainty of predicted process performance due to variations in thermodynamics model parameter estimation from different experimental data sets, Fluid Phase Equilibria. 142 (1998) 115-130. doi:10.1016/S0378-3812(97)00232-X.

[80] V.R. Vasquez, W.B. Whiting, Effect of Systematic and Random Errors in Thermodynamic Models on Chemical Process Design and Simulation: A Monte Carlo Approach, Ind. Eng. Chem. Res. 38 (1999) 3036-3045. doi:10.1021/ie980748e.

[81] B. Efron, Bootstrap Methods: Another Look at the Jackknife, Ann. Stat. 7 (1979) 1-26.

[82] P. Diaconis, B. Efron, Computer-Intensive Methods in Statistics, Sci. Am. 248 (1983) 116-130. doi:10.1038/scientificamerican0583-116.

[83] B. Efron, R. Tibshirani, Bootstrap Methods for Standard Errors, Confidence Intervals, and Other Measures of Statistical Accuracy, Stat. Sci. 1 (1986) 54-75. doi:10.1214/ss/1177013815.

[84] T.J. DiCiccio, B. Efron, Bootstrap confidence intervals, Stat. Sci. 11 (1996) 189-228. doi:10.1214/ss/1032280214.

[85] H.-J. Joo, W. Arlt, Vapor-liquid equilibrium for the binary systems ethylene glycol-n-amyl alcohol and ethylene glycol-isoamyl alcohol, J. Chem. Eng. Data. 26 (1981) 138-140. doi:10.1021/je00024a010.

[86] S.P. Verevkin, Determination of vapor pressures and enthalpies of vaporization of 1,2-alkanediols, Fluid Phase Equilibria. 224 (2004) 23-29. doi:10.1016/j.fluid.2004.05.010.

[87] B. Schmid, M. Döker, J. Gmehling, Measurement of the thermodynamic properties for the reactive system ethylene glycol-acetic acid, Fluid Phase Equilibria. 258 (2007) 115-124. doi:10.1016/j.fluid.2007.05.030.

[88] N. Kamihama, H. Matsuda, K. Kurihara, K. Tochigi, S. Oba, Isobaric Vapor-Liquid Equilibria for Ethanol + Water + Ethylene Glycol and Its Constituent Three Binary Systems, J. Chem. Eng. Data. 57 (2012) 339-344. doi:10.1021/je2008704. 
[89] D. Xu, H. Li, Z. Li, Determination and Modeling of Isobaric Vapor-Liquid Equilibria for the Methylcarbamate + Methyl-N-phenyl Carbamate System at Different Pressures, J. Chem. Eng. Data. 58 (2013) 3110-3117. doi:10.1021/je400551d.

[90] J.D. Olson, D.R. Cordray, Thermodynamics of hydrogen-bonding mixtures: GE, HE, and VE of propylene glycol + ethylene glycol, Fluid Phase Equilibria. 76 (1992) 213-223. doi:10.1016/03783812(92)85089-Q.

[91] M. Cocchi, M. Manfredini, A. Marchetti, S. Sighinolfi, L. Tassi, A. Ulrici, M. Vignali, The Ethane-1,2-diol + 2-methoxyethanol + 1,2-dimethoxyethane Ternary Solvent System: Density and Volume Properties at Different Temperatures, Phys. Chem. Liq. 39 (2001) 481-498. doi:10.1080/00319100108031678.

[92] E. Zorębski, B. Lubowiecka-Kostka, Thermodynamic and transport properties of (1,2-ethanediol + 1nonanol) at temperatures from (298.15 to 313.15) K, J. Chem. Thermodyn. 41 (2009) 197-204. doi:10.1016/j.jct.2008.09.018.

[93] D.I. Sagdeev, M.G. Fomina, G.K. Mukhamedzyanov, I.M. Abdulagatov, Experimental study of the density and viscosity of polyethylene glycols and their mixtures at temperatures from $293 \mathrm{~K}$ to $465 \mathrm{~K}$ and at high pressures up to $245 \mathrm{MPa}$, Fluid Phase Equilibria. 315 (2012) 64-76. doi:10.1016/j.fluid.2011.11.022.

[94] S.O. Derawi, G.M. Kontogeorgis, M.L. Michelsen, E.H. Stenby, Extension of the cubic-plus-association equation of state to glycol-water cross-associating systems, Ind. Eng. Chem. Res. 42 (2003) 14701477. 


\section{Acknowledgements}

The authors gratefully acknowledge the financial support from Statoil A/S (Norway) for this work as part of the research project 'Thermodynamics of Petroleum Fluids relevant to Subsea Processing' as part of the 'Chemicals for Gas Processing' research programme.

\section{Nomenclature}

MEG

DEG

TEG

CPA

SAFT

SRK

$T_{R}$

b

$a_{0}$

$\mathrm{C}_{1}$

$\varepsilon$

$\beta$

$\Gamma$ mono-ethylene glycol

di-ethylene glycol

tri-ethylene glycol

Cubic-Plus-Association (equation of state)

Statistical Associating Fluid Theory (equation of state)

Soave-Redlich-Kwong (equation of state)

Reduced temperature $\left(T_{R}=T / T_{C}\right)$

$[-]$

Co-volume

$\left[\mathrm{cm}^{3} / \mathrm{mol}\right]$

attractive energy term

$\left[\right.$ bar $\mathrm{cm}^{6} / \mathrm{mol}^{2}$ ]

attractive energy temperature-correction

$[-]$

association energy

[bar $\left.\mathrm{cm}^{6} / \mathrm{mol}\right]$

association volume

$[-]$

$=a_{0} /(b \cdot R)$, where $R$ is the universal gas constant
[K] 
$\mathrm{OF}_{\min } \quad$ Objective function (for minimization)

$\mathrm{w}_{\mathrm{i}} \quad$ Regression weight for data type $\mathrm{i}$

VLE Vapour-liquid equilibrium

LLE Liquid-liquid equilibrium

SLE Solid-liquid equilibrium

TPX Data type: VLE (temperature, pressure, liquid composition)

TPxx Data type: LLE (temperature, pressure, liquid composition 1, liquid composition 2)

TPy Data type: VLE (temperature, pressure, vapour composition)

$\mathrm{BIP} / \mathrm{k}_{\mathrm{ij}} \quad$ Binary interaction parameter

$\mathrm{P}_{\text {Sat }} \quad$ Saturated vapour pressure $\quad[\mathrm{bar}]$

$\rho$

Density / Pure component saturated density $\quad\left[\mathrm{mol} / \mathrm{cm}^{3}\right]$

AARD Absolute Average Relative Deviation $\left(A A R D=\frac{1}{n} \sum\left|\frac{i_{c a l c}-i_{\text {exp }}}{i_{\text {exp }}}\right|\right)$

ARD Average Relative Deviation $\left(A R D=\frac{1}{n} \sum \frac{i_{c a l c}-i_{\text {exp }}}{i_{\text {exp }}}\right)$

ppm parts per million (molar) 


\section{Appendix A: Data tables}

Parameter sets and confidence intervals

$<<$ Tables A1-A4 >>

Data fit errors for optimization and uncertainty analysis

$<<$ Tables A5 >> 
Figures

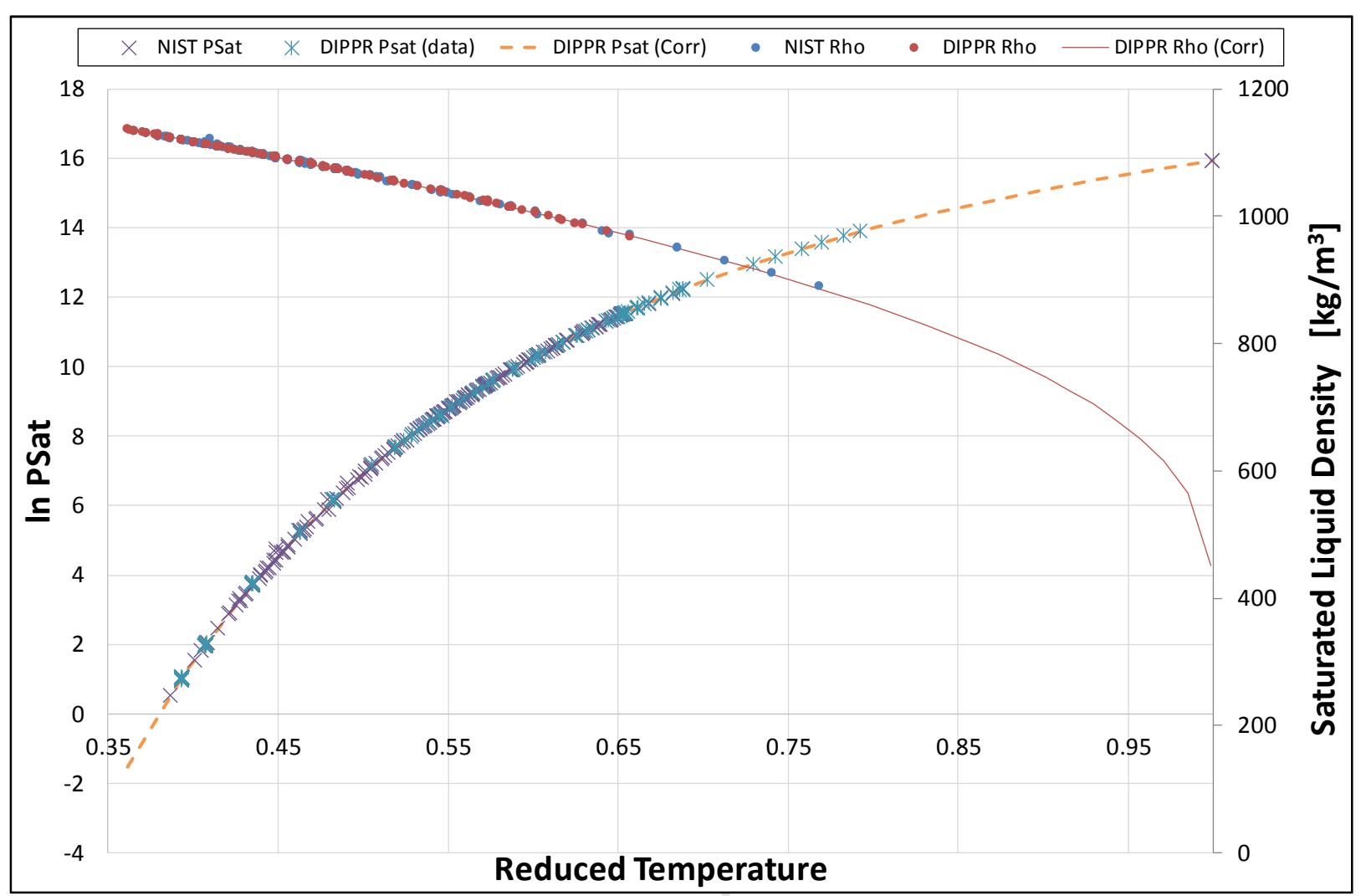

Figure 1: NIST and DIPPR data for the saturated vapour pressure (left axis) and liquid density (right axis) of MEG 


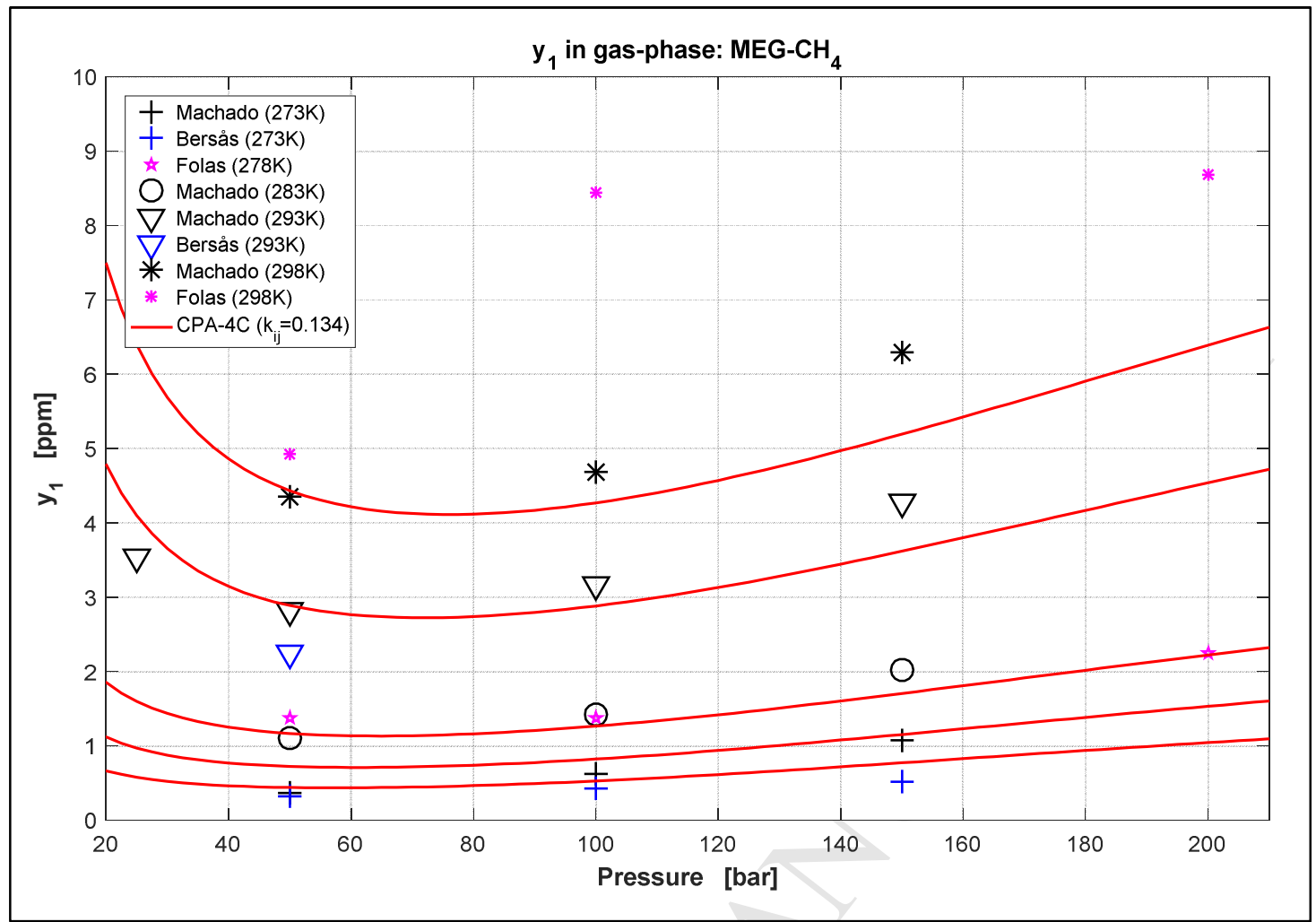

Figure 2: Comparison of literature data sources for $\mathrm{MEG}$ in $\mathrm{CH}_{4}$ (gas phase)

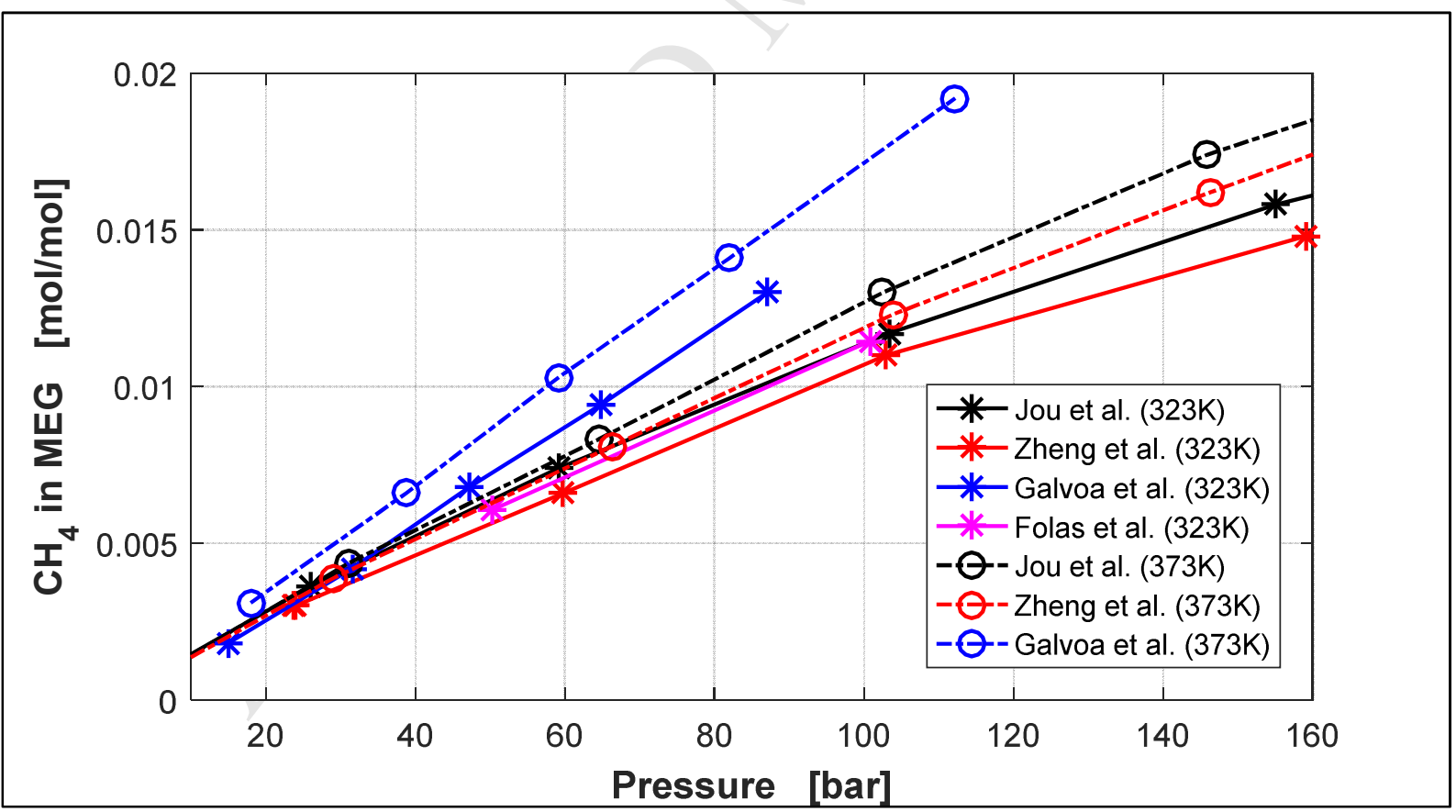

Figure 3: Selected $\mathrm{CH}_{4}$ in $\mathrm{MEG}$ solubility data at 323 and $373 \mathrm{~K}$ (data are connected with lines in order to illustrate relative trends) 


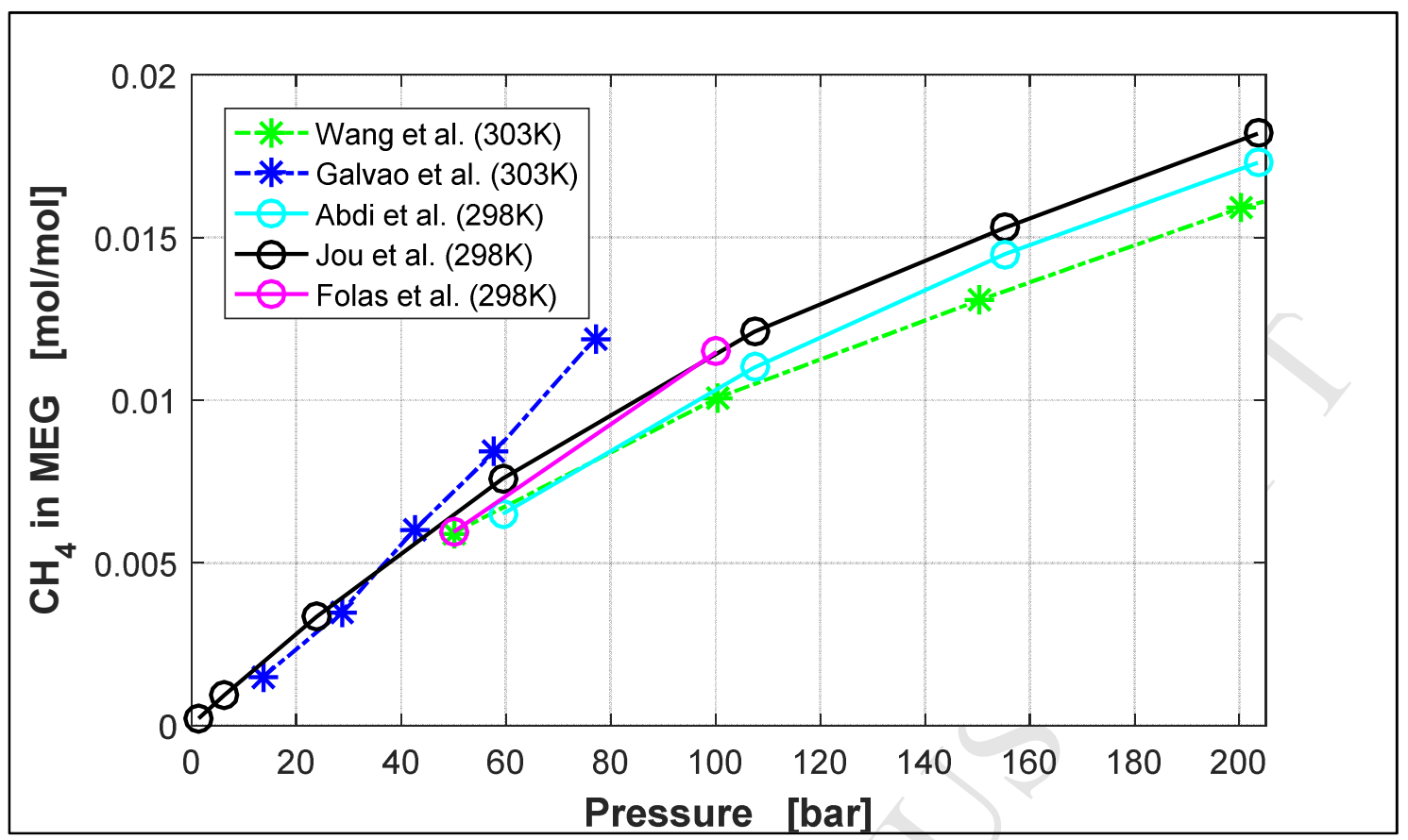

Figure 4: Selected $\mathrm{CH}_{4}$ in $\mathrm{MEG}$ solubility data at 298 and $303 \mathrm{~K}$ (data are connected with lines in order to illustrate relative trends)

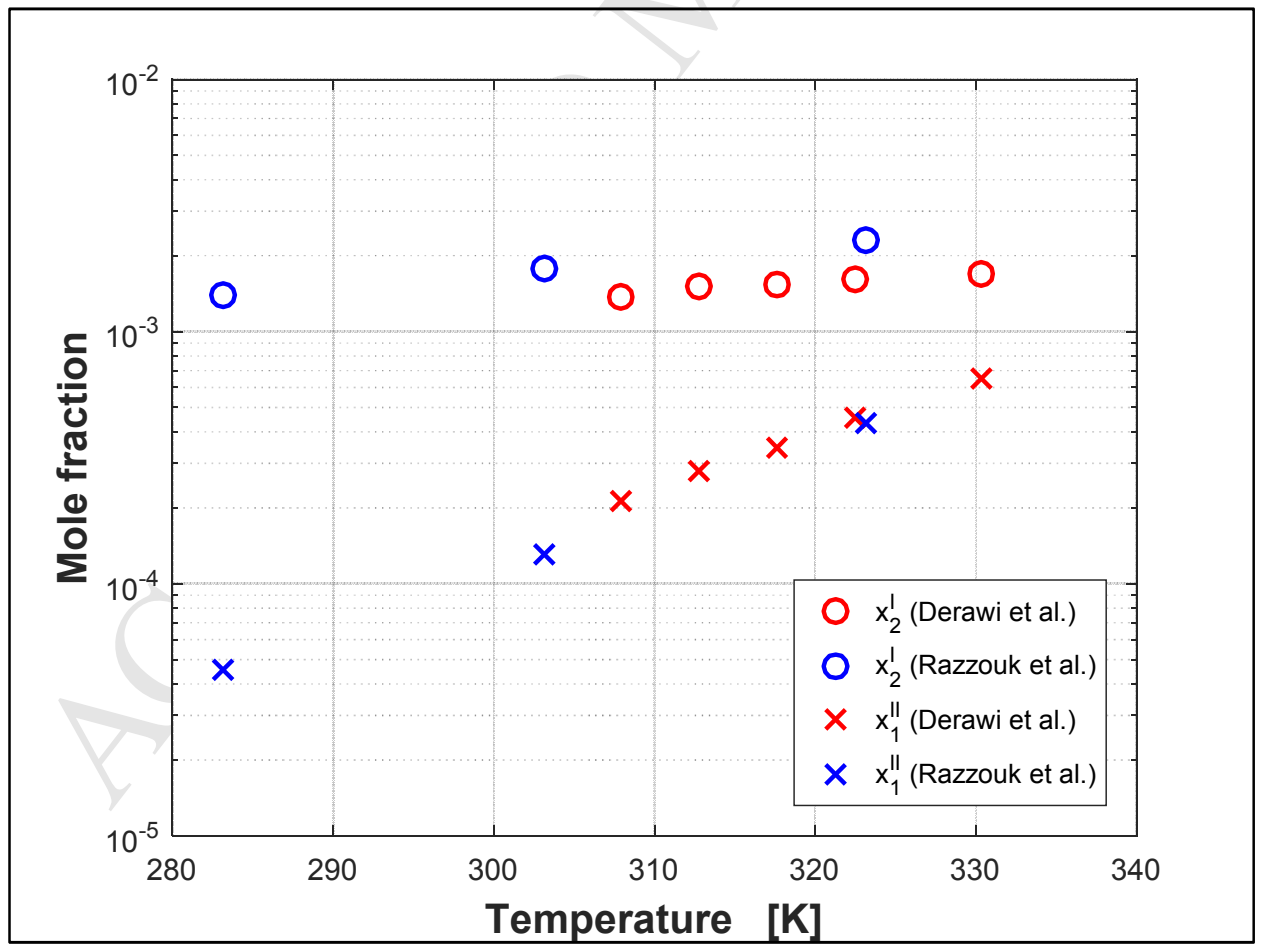

Figure 5: Comparison of MEG-nC6 LLE data from Derawi et al. [41] and Razzouk et al. [42] 


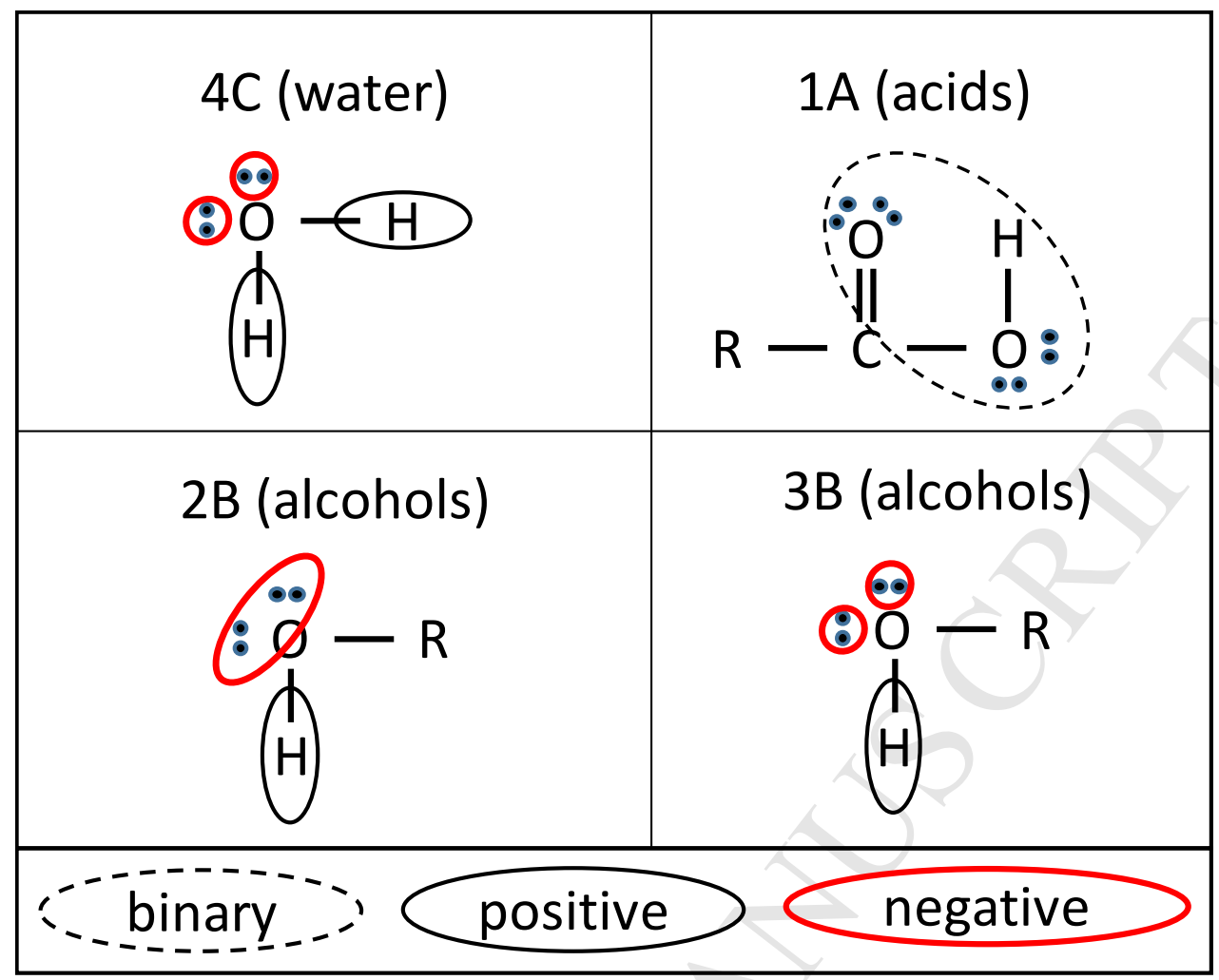

Figure 6: Standardization ${ }^{6}$ of association schemes first shown by Huang \& Radosz [53]

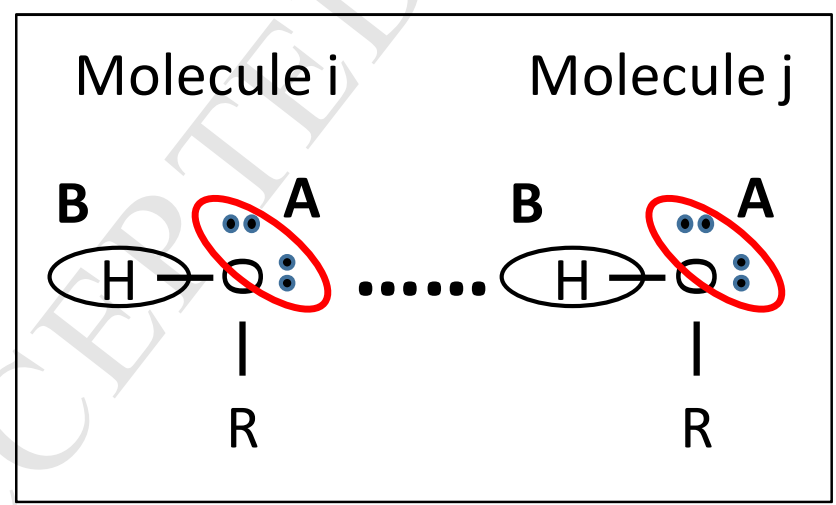

Figure 7: Representation of association between two $2 B$ molecules

\footnotetext{
${ }^{6}$ The "binary, positive and negative" was not used by Huang \& Radosz, but is utilized as a method for characterizing the association/attraction between various sites: positive will attract negative and vice versa, while binary sites interact with all other sites
} 


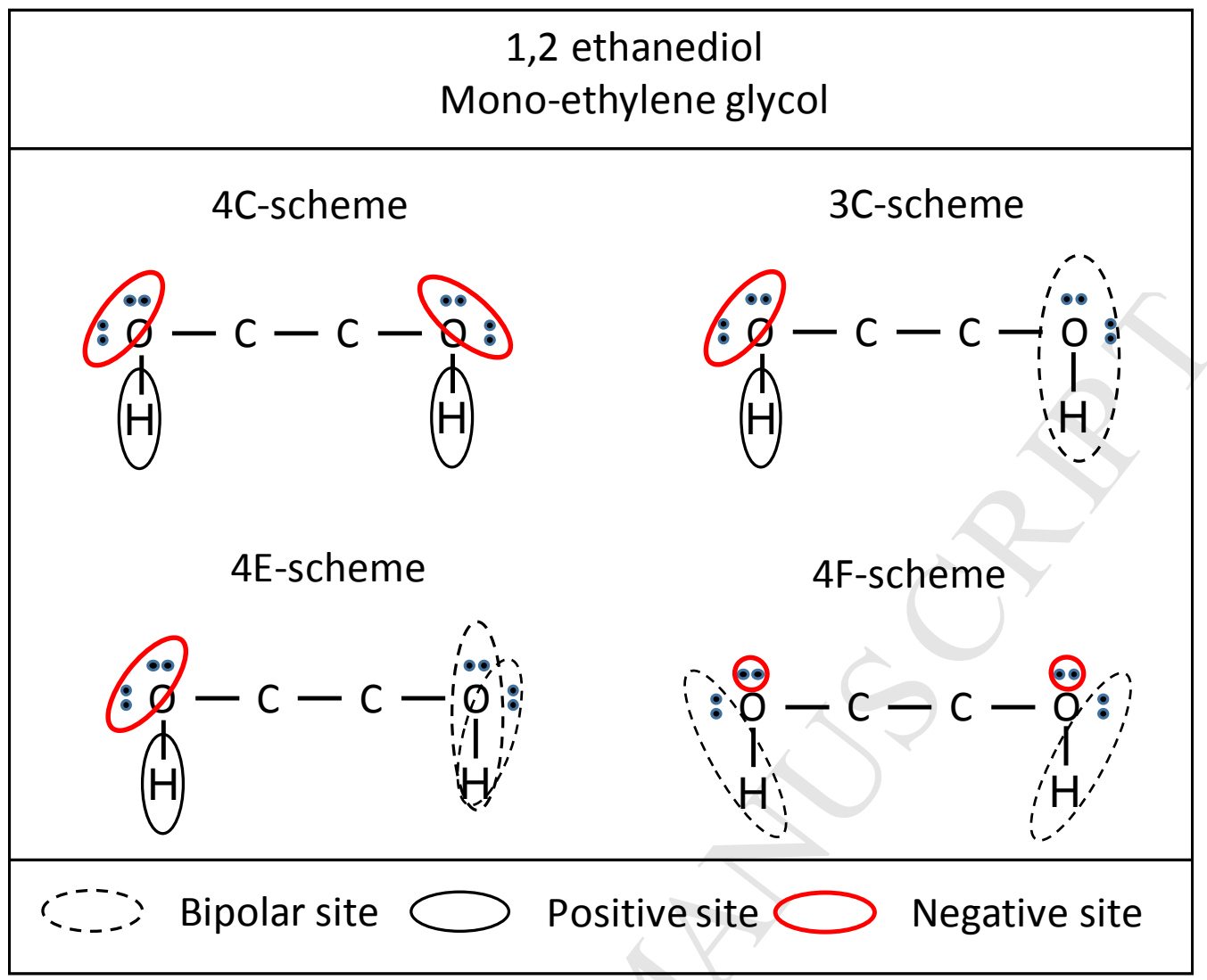

Figure 8: New association schemes for MEG 


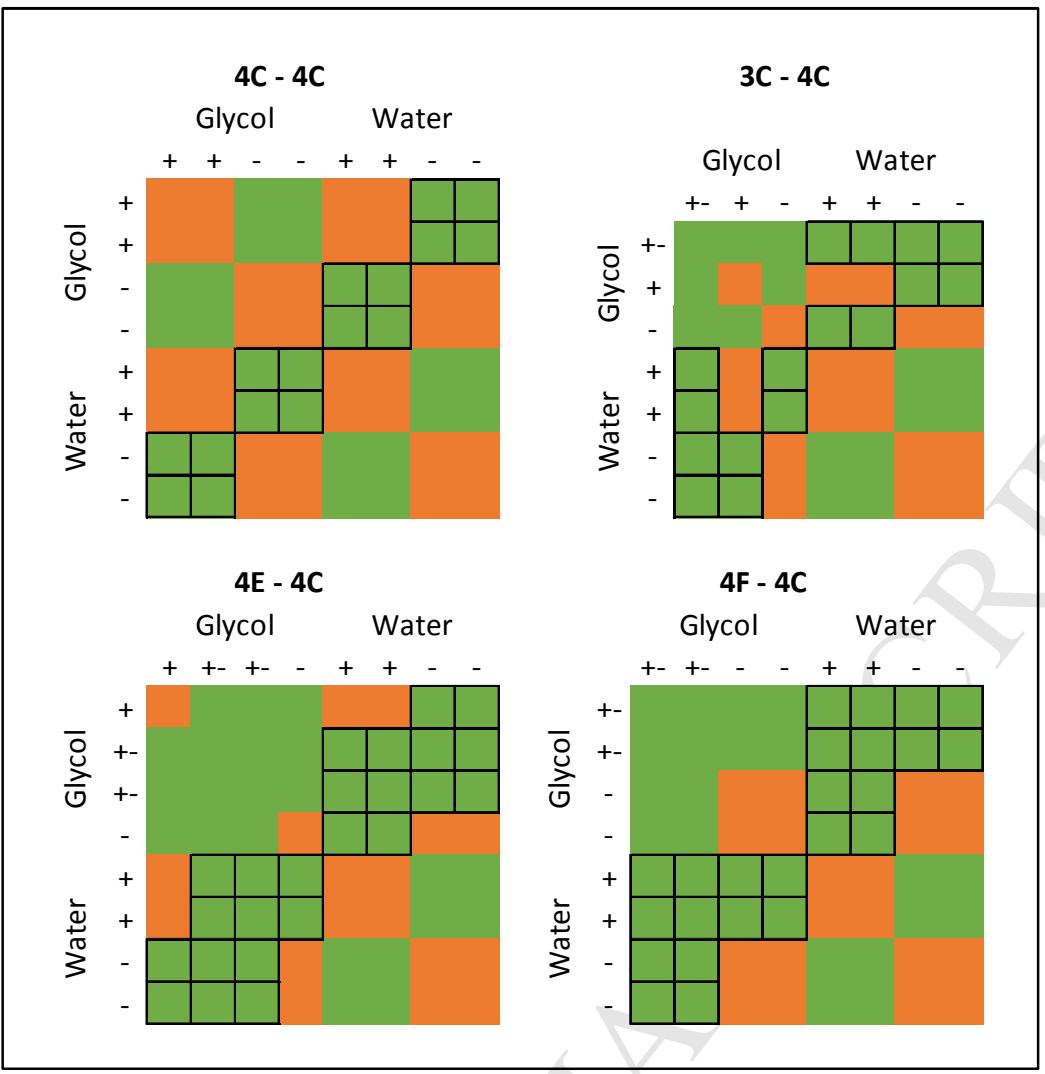

Figure 9: Association dynamics for MEG with 4C-water under various association schemes (Legend: orange = no association, green = self-association, green with border $=$ cross-association)

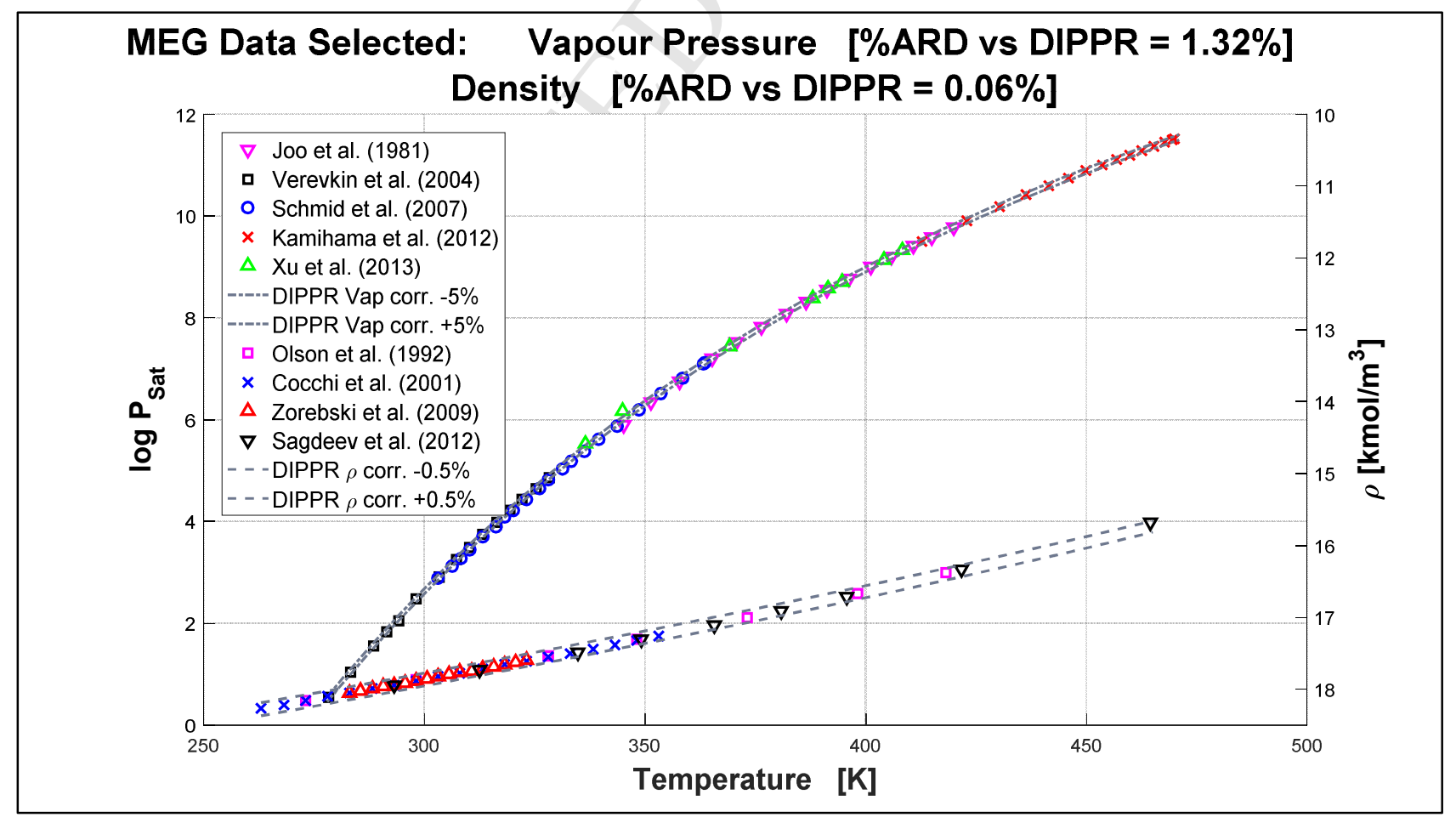

Figure 10: Pure component MEG data selected for parameter fitting procedure 

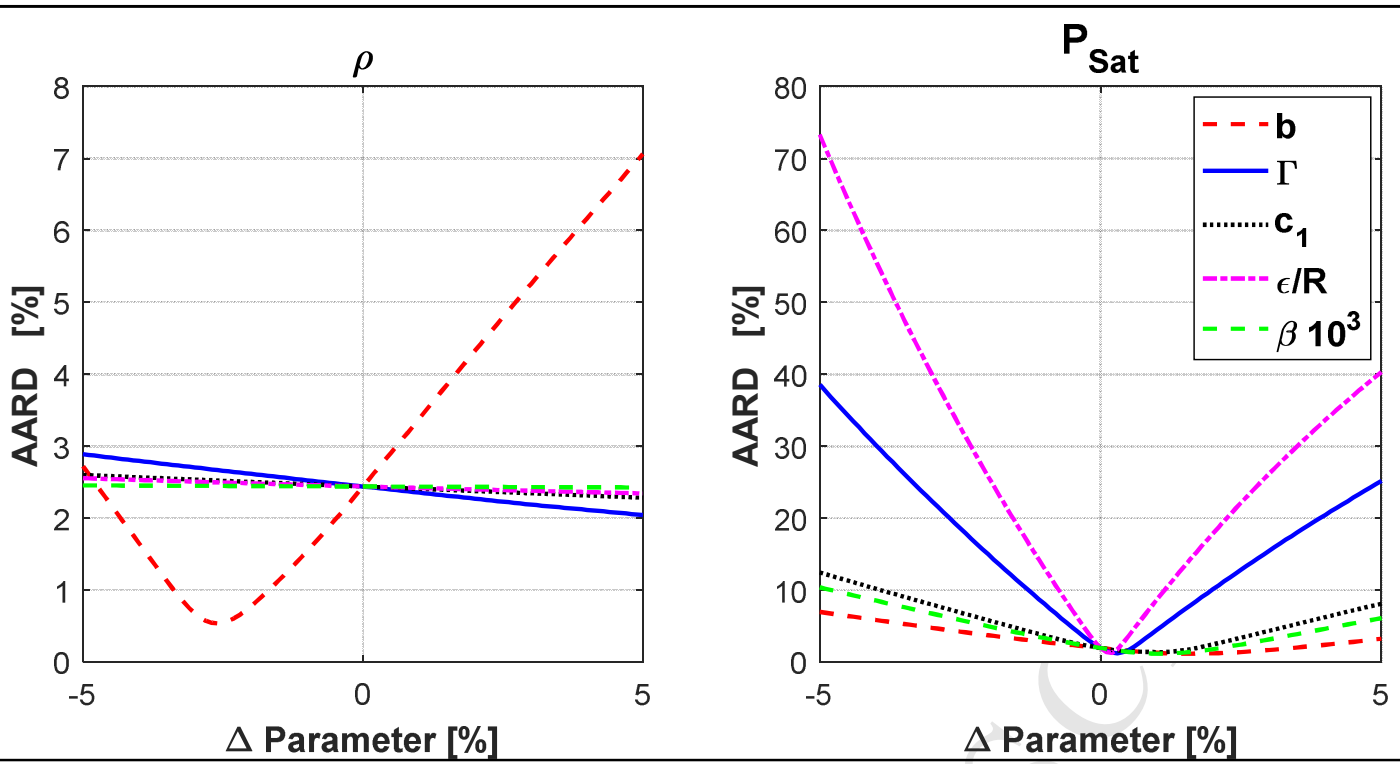

Figure 11: Single parameter sensitivity analysis for pure MEG density and vapour pressure using the literature $4 C$ parameters 

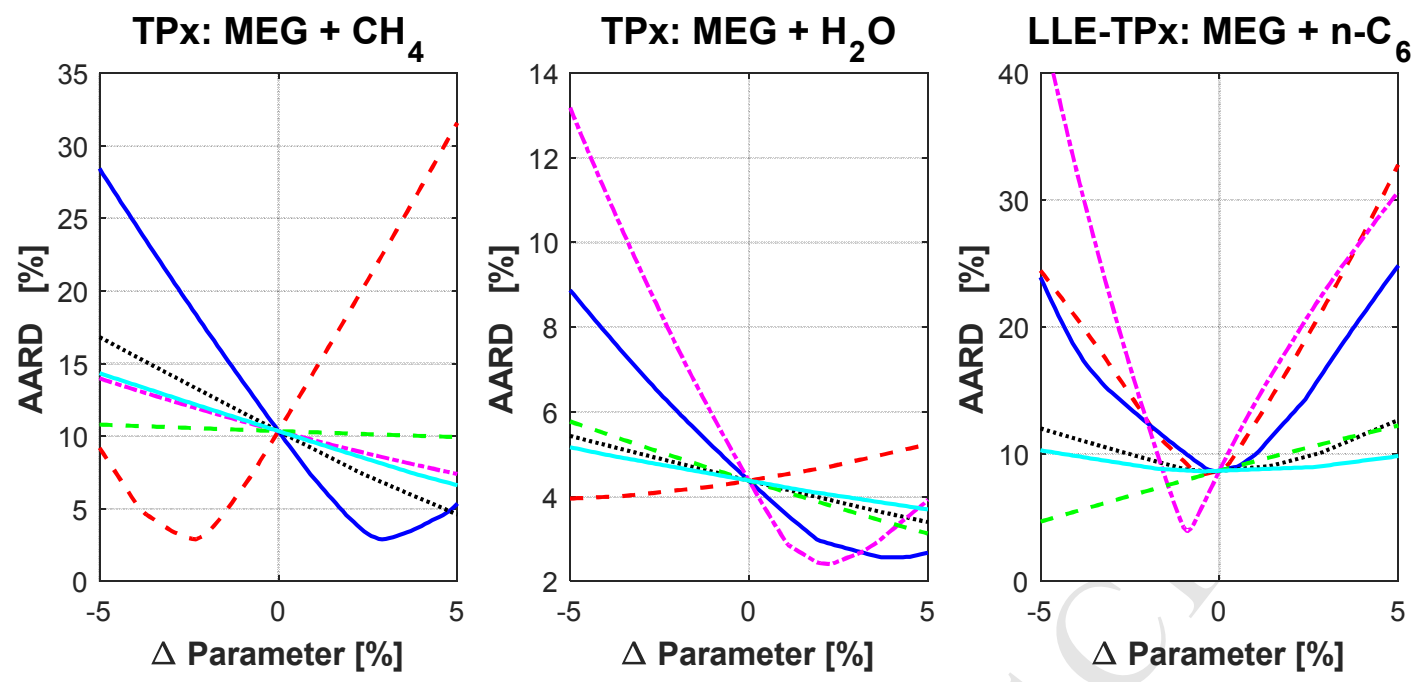

TPy: $M E G+\mathrm{CH}_{4}$

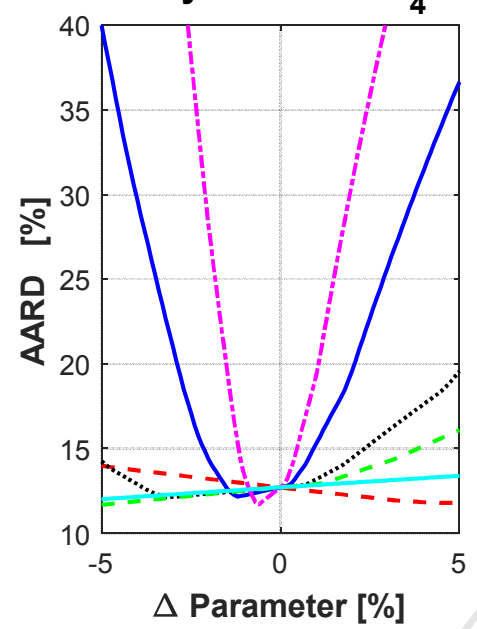

TPy: $M E G+\mathrm{H}_{2} \mathrm{O}$

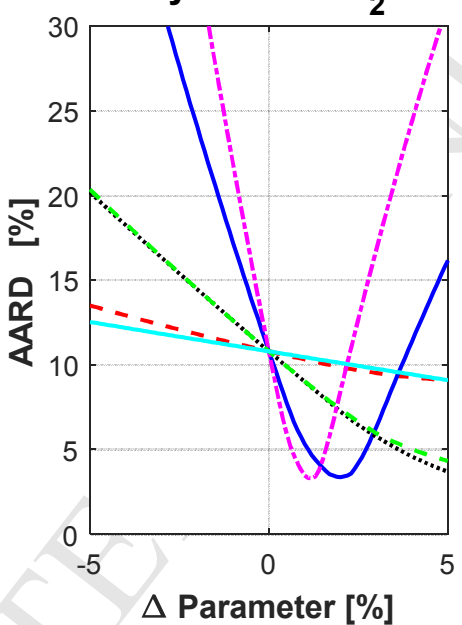

LLE-TPx: $M E G+n-C_{7}$

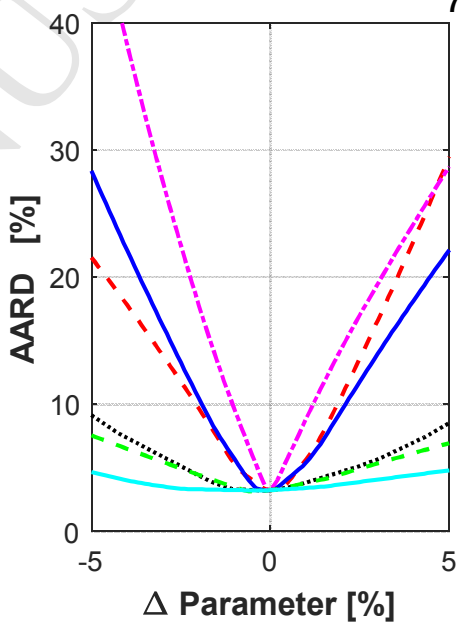

$---b-\Gamma \cdots \cdots \cdots \cdot c_{1}----\epsilon / R^{---} \beta 10^{3}-k_{i j}$

Figure 12: Single parameter sensitivity analysis for binary MEG VLE and LLE using the literature 4 C parameters 


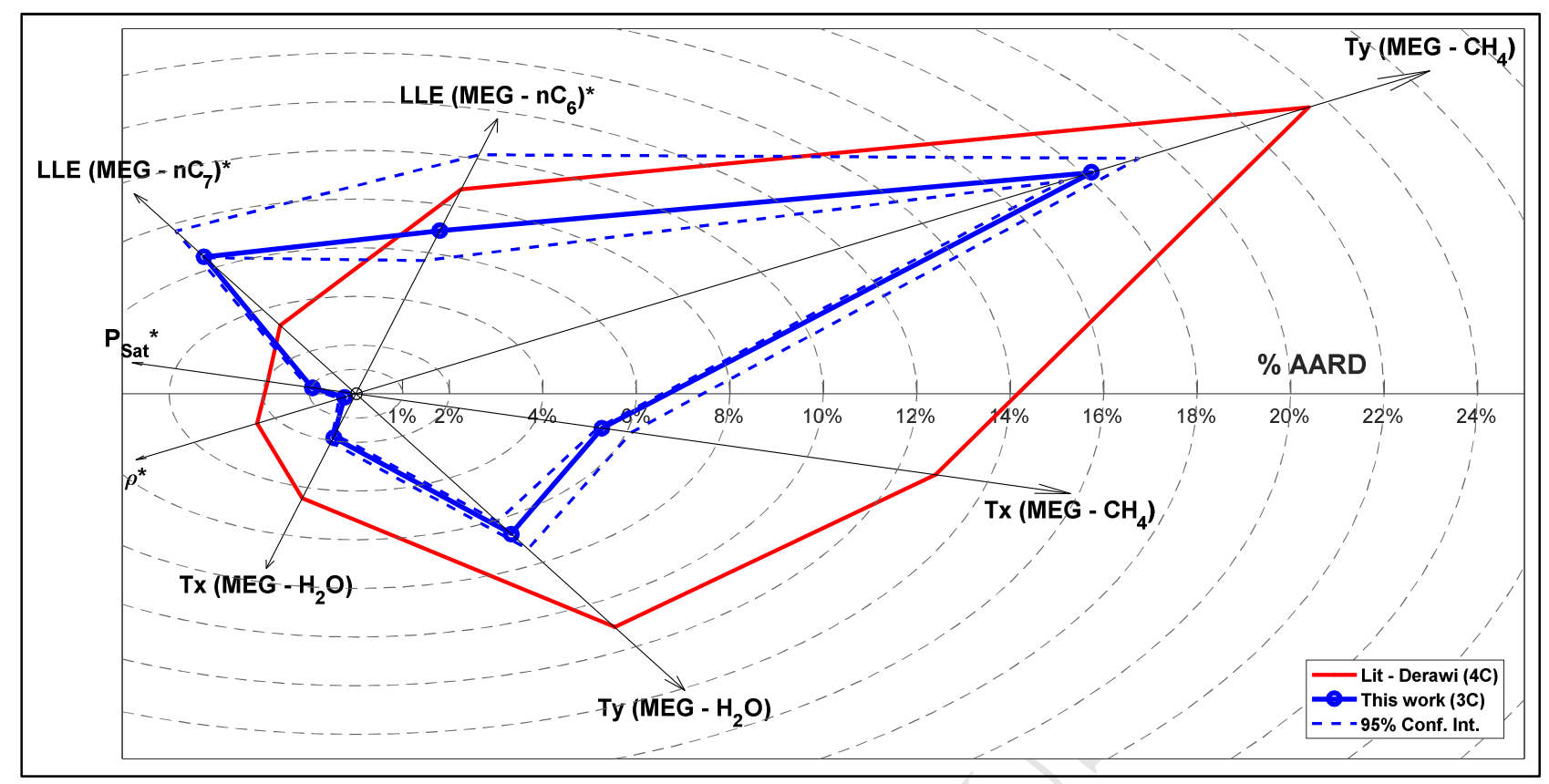

Figure 13: Radar plot and uncertainty analysis for the new 3 Cassociation scheme

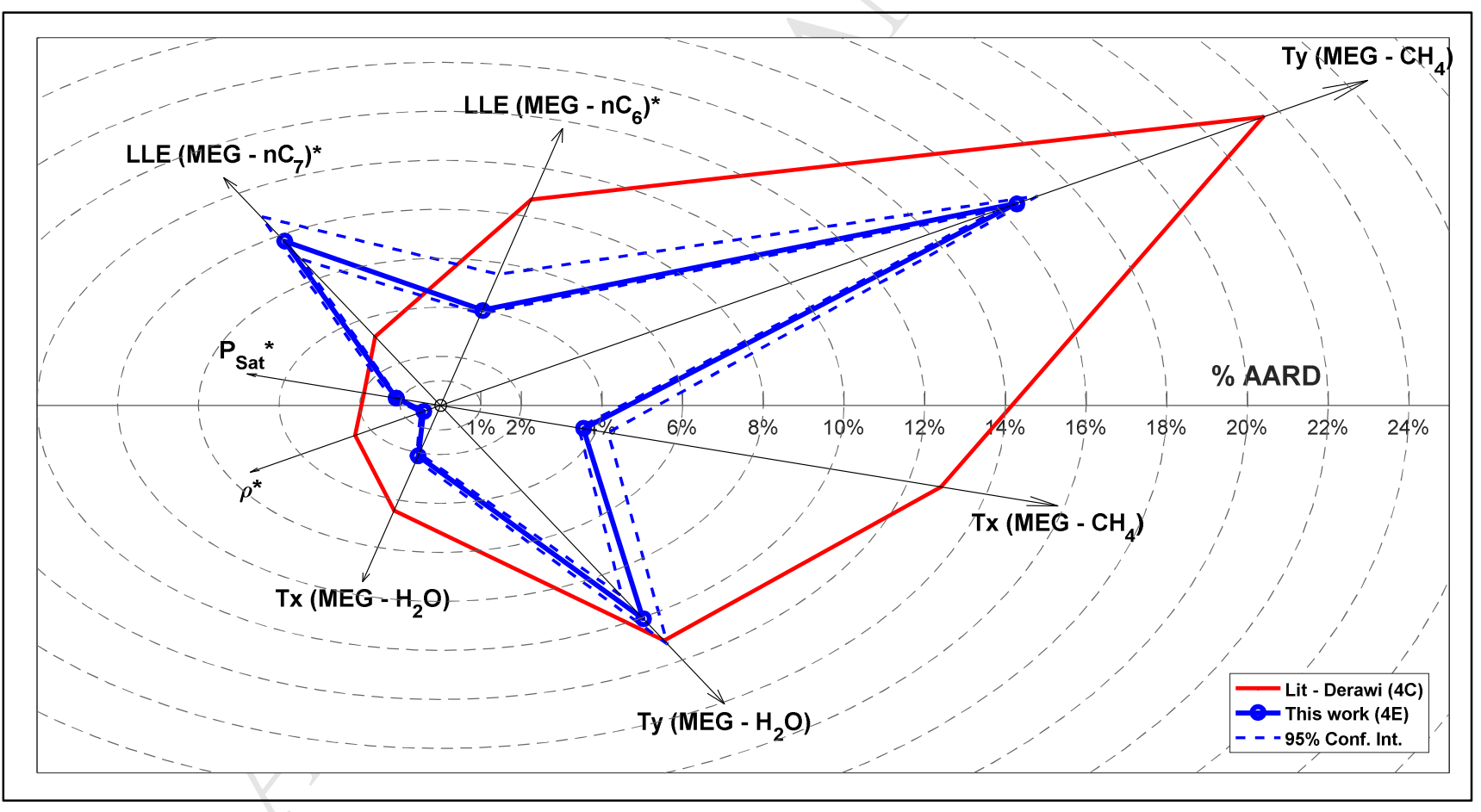

Figure 14: Radar plot and uncertainty analysis for the new 4E association scheme 


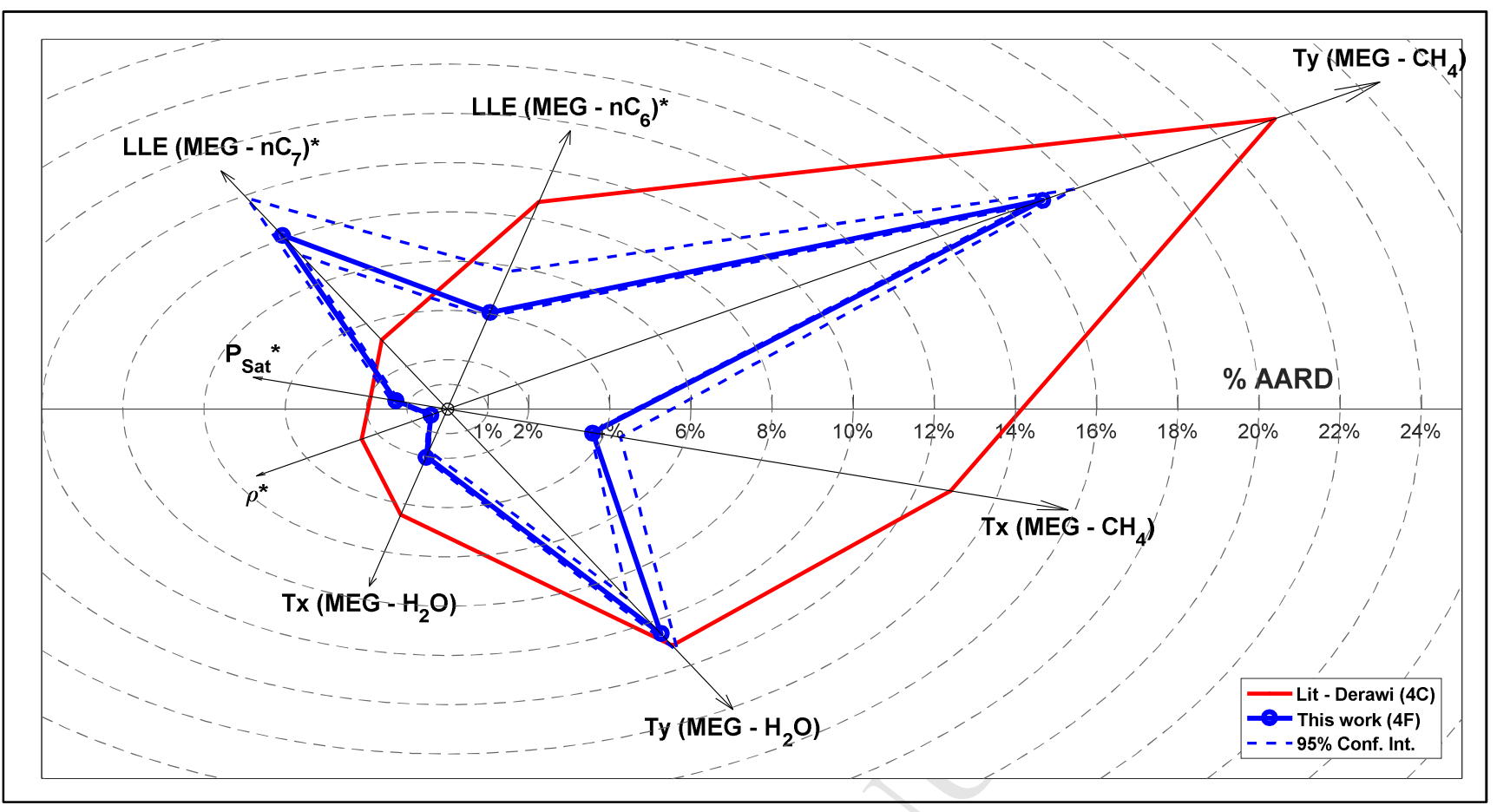

Figure 15: Radar plot and uncertainty analysis for the new $4 F$ association scheme

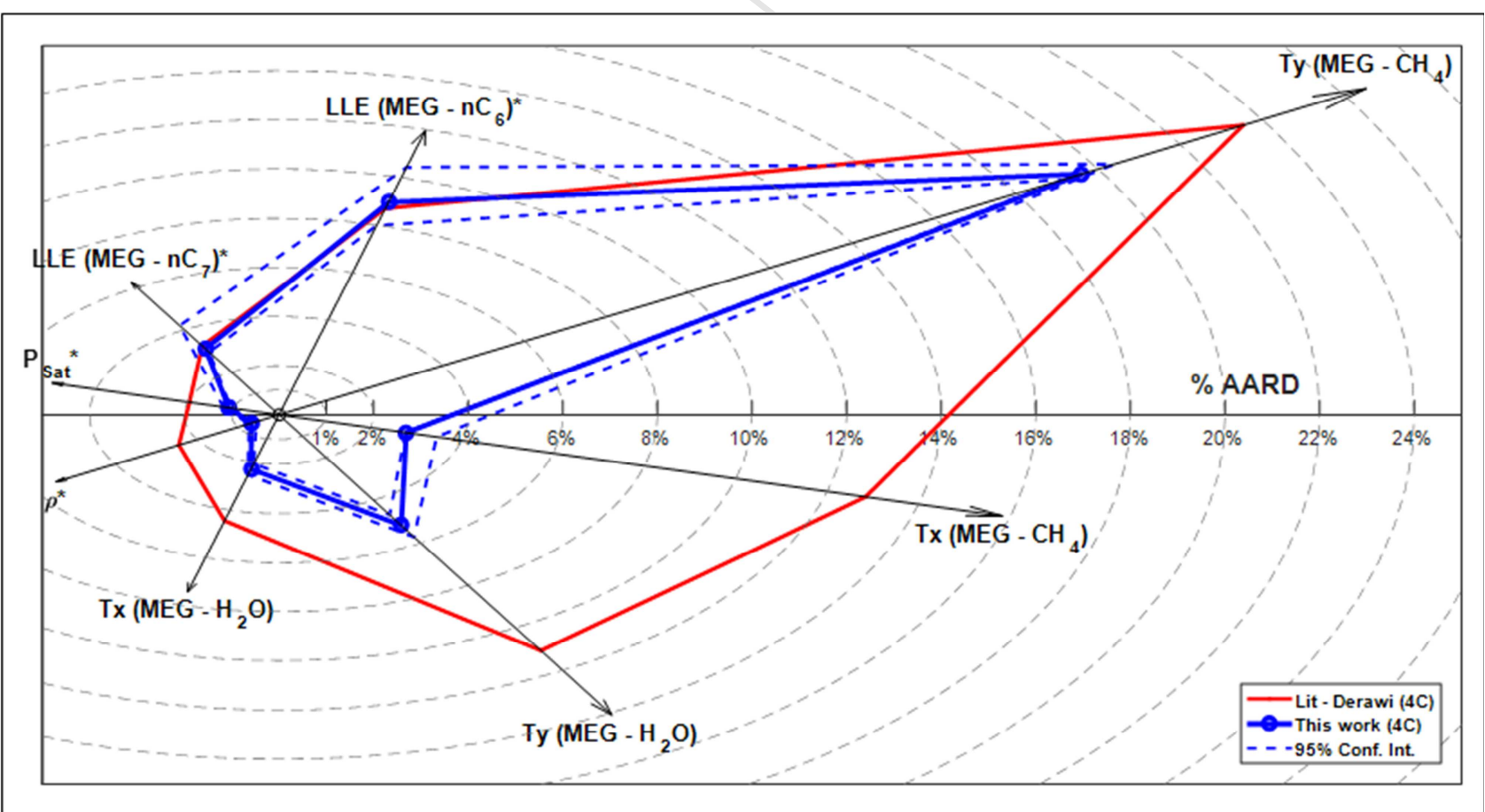

Figure 16: Radar plot and uncertainty analysis for the new $4 C$ parameters 


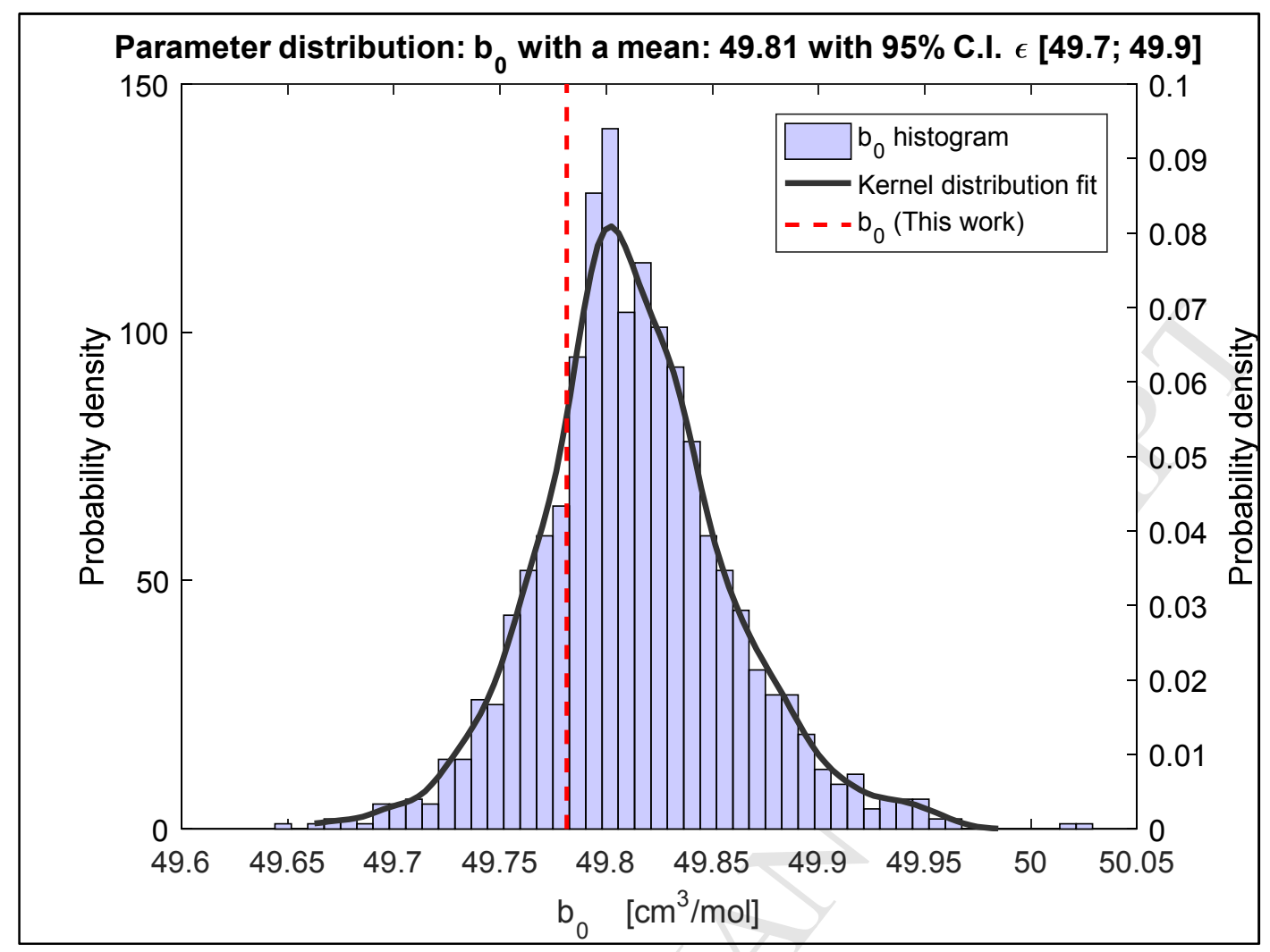

Figure 17: Distribution of the co-volume for the parameterization of the $3 \mathrm{C}$ scheme

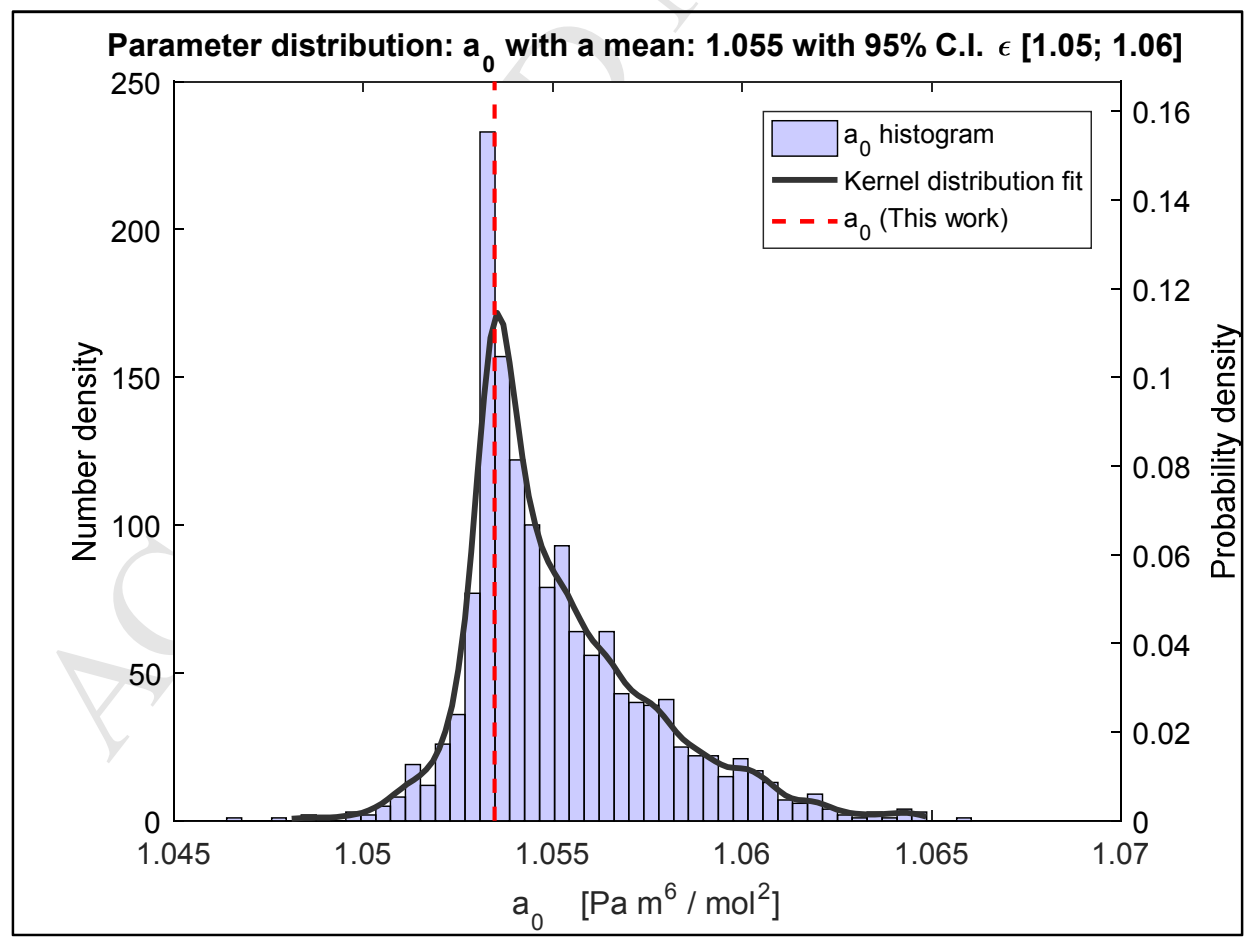

Figure 18: Distribution of the co-volume for the parameterization of the $4 C$ scheme 


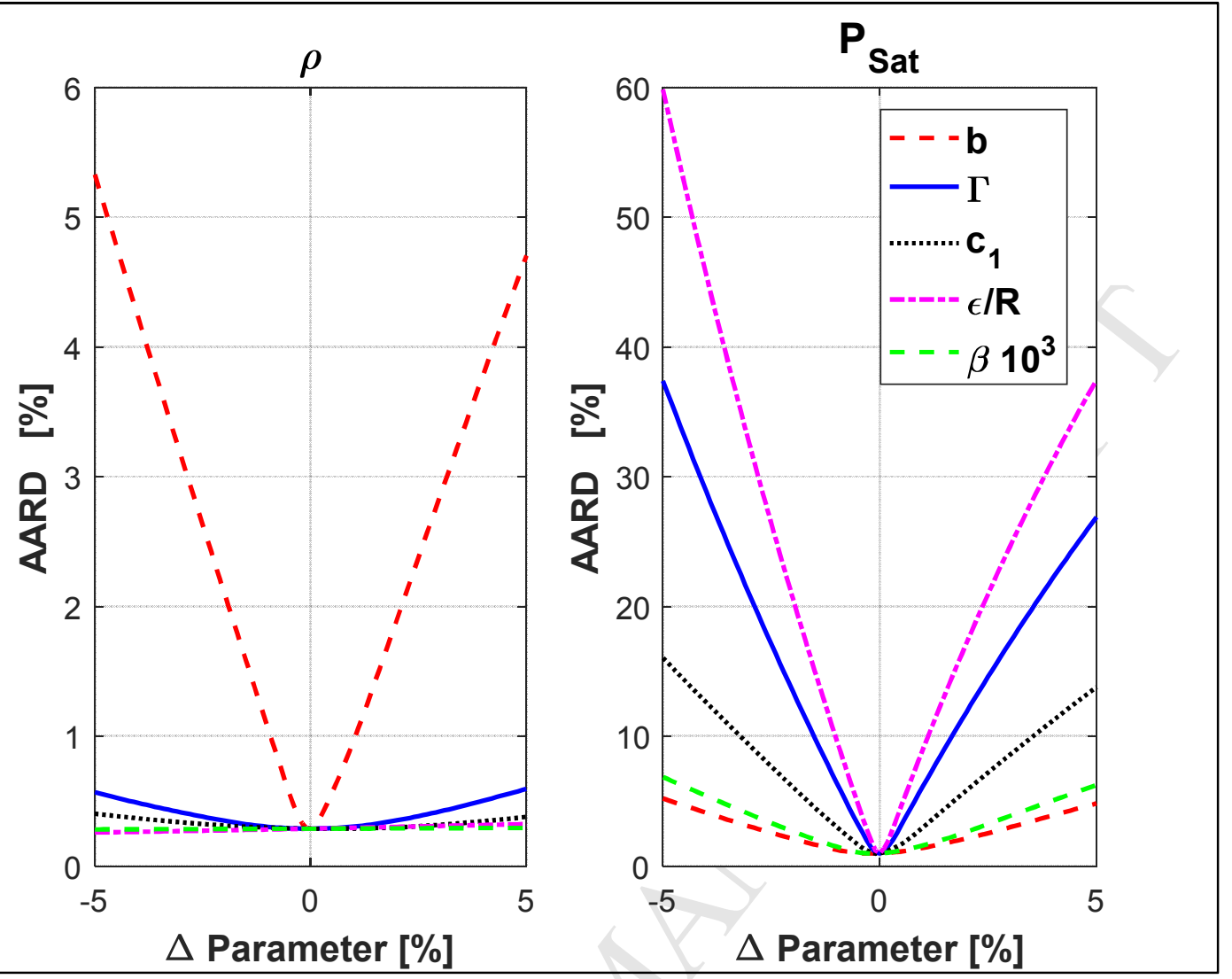

Figure 19: Single parameter sensitivity analysis for pure MEG density and vapour pressure using the new 3C association scheme 

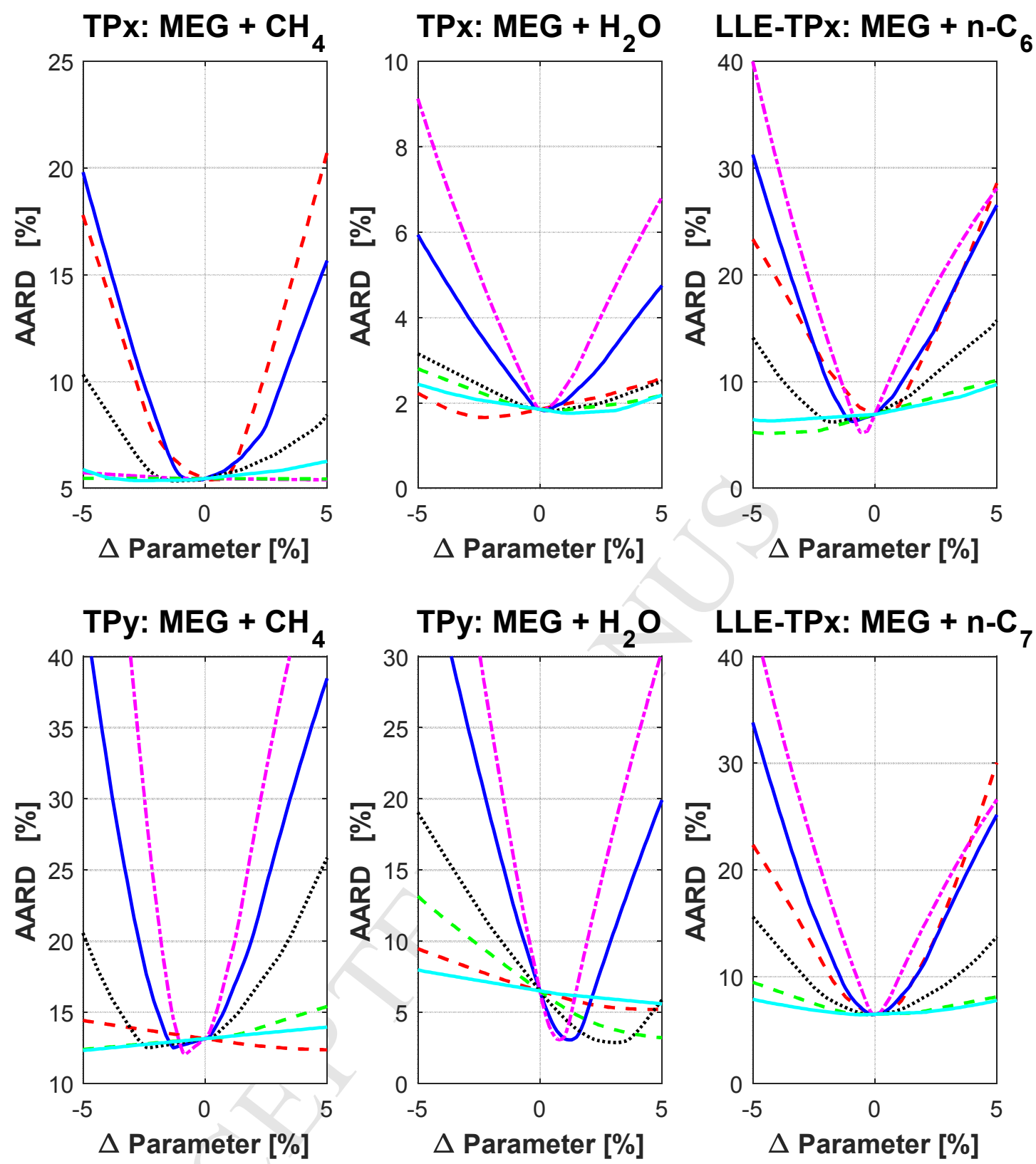

$$
---b-\Gamma \cdots \cdots \cdot c_{1}-\cdot--\epsilon / R---\beta 10^{3}-\mathbf{k}_{i j}
$$

Figure 20: Single parameter sensitivity analysis for binary MEG VLE and LLE using the new 3C association scheme 


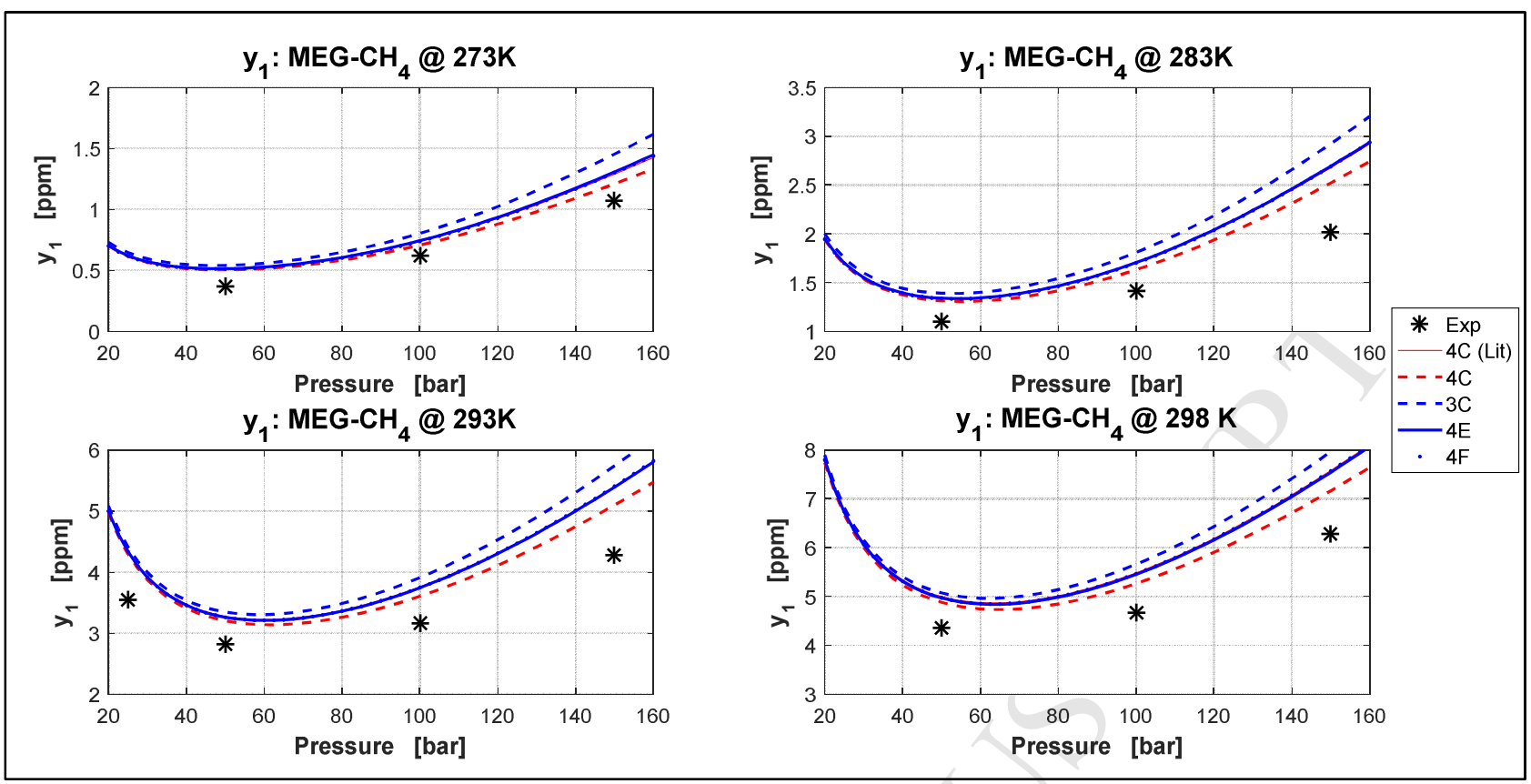

Figure 21: Comparison of various association schemes for modelling of MEG-CH 4 TPy data (Miguens et al. [40]) without BIPS

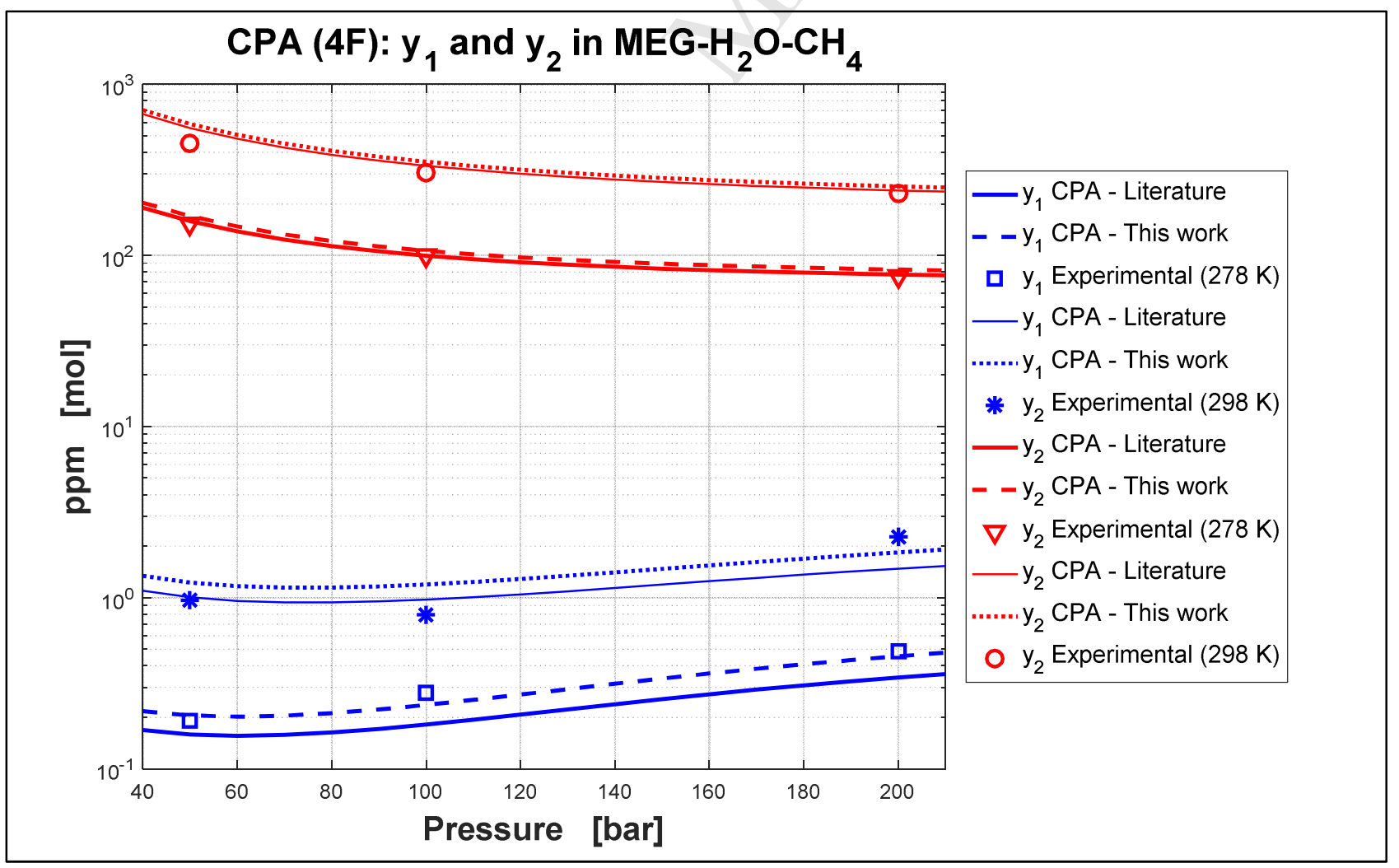

Figure 22: Modelling of gas phase composition for $\mathrm{MEG}-\mathrm{H}_{2} \mathrm{O}-\mathrm{CH}_{4}$, comparing the literature $4 \mathrm{C}$ (solid lines) and new $4 \mathrm{~F}$ (dashed lines) association schemes using BIPs fitted to vapour phase om Table 3 


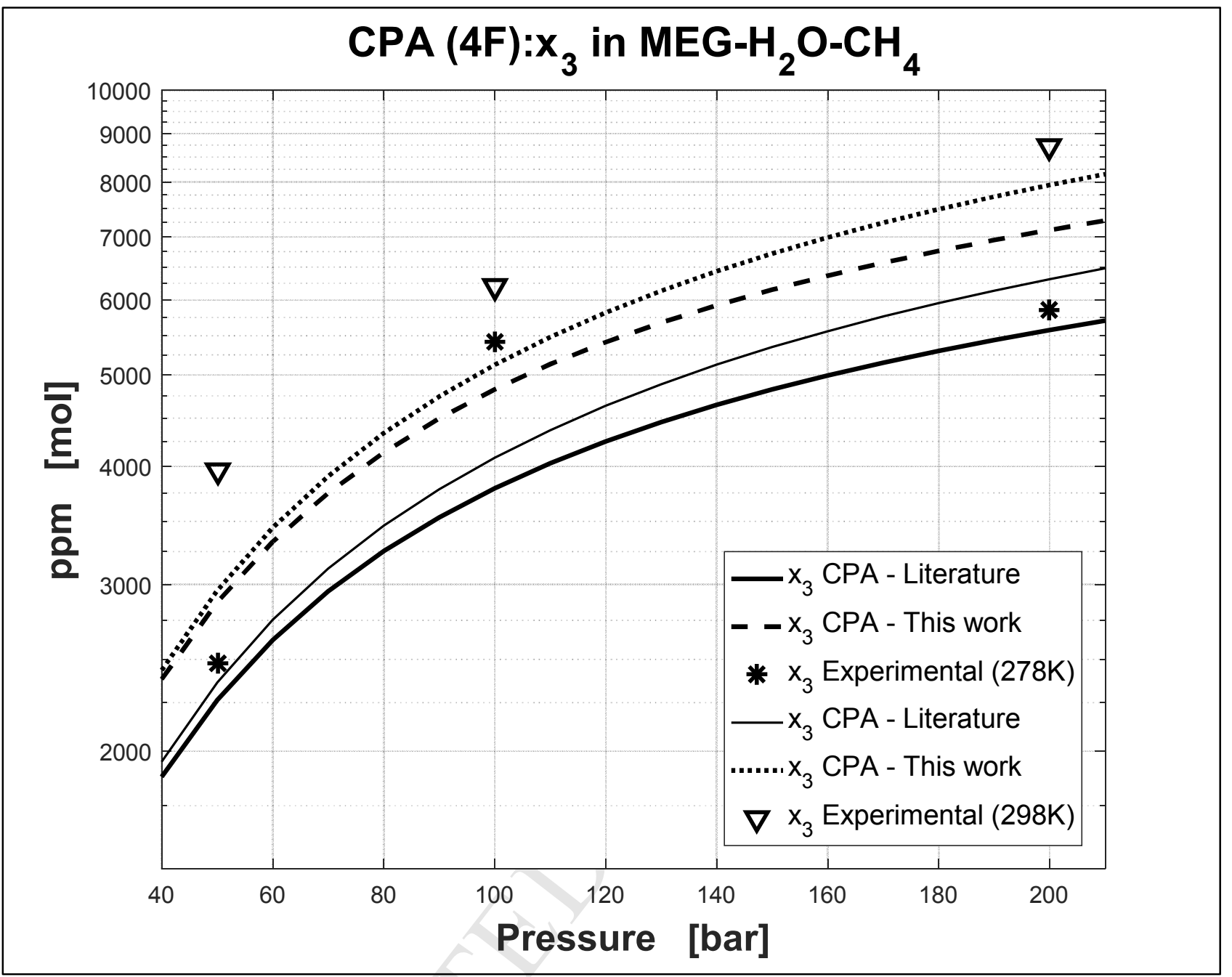

Figure 23: Modelling of liquid phase composition for $\mathrm{MEG}-\mathrm{H}_{2} \mathrm{O}-\mathrm{CH}_{4}$, comparing the literature $4 \mathrm{C}$ (solid lines) and new $4 \mathrm{~F}$ (dashed lines) association schemes using BIPs fitted to vapour phase from Table 3 


\section{Tables}

Table 1: Literature CPA parameters for MEG and TEG

\begin{tabular}{cccccccc} 
Parameter & $\begin{array}{c}\mathbf{b}_{\mathbf{0}} \\
{\left[\mathbf{c m}^{3} / \mathbf{m o l}\right]}\end{array}$ & $\boldsymbol{\Gamma}[\mathrm{K}]$ & $\mathbf{c}_{\mathbf{1}}$ & $\boldsymbol{\varepsilon} / \mathbf{R}[\mathrm{K}]$ & $\boldsymbol{\beta} \mathbf{1 0}^{\mathbf{3}}$ & \multicolumn{2}{c}{ Dev. vs DIPPR (\%) } \\
& & & & & $\mathbf{P}_{\text {SAT }}$ & $\boldsymbol{\rho}$ \\
\hline MEG & 51.4 & 2531.7 & 0.6744 & 2375.8 & 14.1 & 0.90 & 1.58 \\
TEG (4C) & 132.1 & 3562.5 & 1.1692 & 1724.4 & 18.8 & 3.04 & 1.61 \\
TEG (4C) & 128.9 & 3622.5 & 0.9676 & 1697.1 & 19.8 & 39.9 & 2.9 \\
TEG (6D) & 128.9 & 3622.5 & 0.9100 & 1420.0 & 20.0 & 28.1 & 4.5 \\
\hline
\end{tabular}

Table 2: Density prediction errors for the CPA-EOS over an extended pressure and temperature range (Data from Crespo et al. [33])

\begin{tabular}{l|cccccccccc} 
& \multicolumn{10}{|c}{ Error in density prediction [\%ARD] } \\
\multicolumn{1}{c}{ T [K] } & $\mathbf{2 8 3 . 1 1}$ & $\mathbf{2 9 3 . 1 3}$ & $\mathbf{3 0 3 . 1 3}$ & $\mathbf{3 1 3 . 1 6}$ & $\mathbf{3 2 3 . 1 5}$ & $\mathbf{3 3 3 . 1 8}$ & $\mathbf{3 4 3 . 1 6}$ & $\mathbf{3 5 3 . 1 8}$ & $\mathbf{3 6 3 . 1 8}$ & \%AARD \\
\hline $\mathbf{4 C}$ (Lit) & -3.43 & -3.22 & -3.03 & -2.84 & -2.66 & -2.46 & -2.26 & -2.07 & -1.86 & 2.65 \\
$\mathbf{3 C}$ & -0.61 & -0.47 & -0.34 & -0.20 & -0.08 & 0.05 & 0.18 & 0.31 & 0.45 & 0.32 \\
$\mathbf{4 C}$ & -0.50 & -0.28 & -0.09 & 0.12 & 0.31 & 0.51 & 0.71 & 0.92 & 1.14 & 0.54 \\
$\mathbf{4 E}$ & -0.89 & -0.69 & -0.51 & -0.33 & -0.16 & 0.03 & 0.21 & 0.39 & 0.59 & 0.46 \\
$\mathbf{4 F}$ & -0.73 & -0.54 & -0.36 & -0.19 & -0.02 & 0.16 & 0.33 & 0.51 & 0.70 & 0.44 \\
\hline
\end{tabular}

Table 3: BIPs for MEG-CH $\mathrm{CH}_{4}$ and MEG- $\mathrm{H}_{2} \mathrm{O}$ estimated using vapour phase binary VLE data

\begin{tabular}{|c|c|c|c|c|c|}
\hline Scheme & $4 C$ (Lit) & $3 C$ & $4 C$ & $4 \mathrm{E}$ & $4 \mathrm{~F}$ \\
\hline$k_{i j} M$ EG-CH & 0.0866 & 0.1098 & 0.0682 & 0.0855 & 0.0851 \\
\hline$k_{i j}$ MEG- $\mathrm{H}_{2} \mathrm{O}$ & -0.1284 & -0.146 & -0.1184 & -0.0543 & -0.0512 \\
\hline
\end{tabular}

Table 4: Prediction errors for various CPA association schemes versus the ternary $\mathrm{MEG}-\mathrm{H}_{2} \mathrm{O}-\mathrm{CH}_{4}$ data of Folas et al. [14]

\begin{tabular}{|c|c|c|c|c|c|c|c|c|c|}
\hline & \multicolumn{3}{|c|}{ \%AARD (no k $\left.k_{i j}\right)$} & \multicolumn{3}{|c|}{ \%AARD (with TPx $k_{i j}$ ) } & \multicolumn{3}{|c|}{ \%AARD (with TPy $k_{i j}$ ) } \\
\hline & $\mathbf{Y}_{\text {MEG }}$ & $\mathrm{Y}_{\mathrm{H} 2 \mathrm{O}}$ & $\mathbf{X}_{\mathrm{CH} 4}$ & $\mathbf{Y}_{\text {MEG }}$ & $\mathrm{YH}_{20}$ & $\mathbf{X}_{\mathrm{CH} 4}$ & YMEG $_{\text {ME }}$ & $У_{\mathrm{H} 2 \mathrm{O}}$ & $\mathrm{X}_{\mathrm{CH} 4}$ \\
\hline 4C (Lit) & 101.1 & 22.1 & 41.0 & 27.4 & 7.4 & 33.8 & 20.8 & 6.1 & 18.8 \\
\hline $3 C$ & 142.8 & 24.5 & 38.8 & 23.7 & 6.5 & 37.0 & 20.2 & 5.8 & 29.9 \\
\hline $4 C$ & 87.3 & 21.1 & 32.1 & 25.4 & 7.2 & 28.8 & 20.0 & 6.7 & 18.7 \\
\hline $4 E$ & 62.5 & 19.3 & 28.4 & 21.5 & 14.4 & 18.3 & 17.4 & 14.4 & 16.9 \\
\hline $4 F$ & 62.7 & 13.6 & 31.5 & 21.3 & 13.9 & 16.8 & 16.4 & 9.4 & 16.3 \\
\hline
\end{tabular}


Table A 1: New 3C parameters along with bootstrapped mean, 95\% lower bound and 95\% upper bound confidence intervals

\begin{tabular}{|c|c|c|c|c|c|c|c|c|c|}
\hline & \multicolumn{9}{|c|}{ Parameters } \\
\hline & {$\left[\mathrm{cm}^{3} / \mathrm{mol}\right]$} & $\Gamma[\mathrm{K}]$ & $c_{1}$ & $\varepsilon / \mathrm{R}[\mathrm{K}]$ & $\beta 10^{3}$ & $\mathrm{k}_{\mathrm{ij}} \mathrm{CH}_{4}$ & $\mathrm{k}_{\mathrm{ij}} \mathrm{H}_{2} \mathrm{O}$ & $k_{i j} n-C_{6}$ & $k_{i j} n-C_{7}$ \\
\hline Set: $3 C$ & 49.78 & 2182.85 & 1.054 & 2602.6 & 17.58 & 0.157 & -0.134 & 0.073 & 0.064 \\
\hline Bootstrap $\mu$ & 49.81 & 2180.88 & 1.055 & 2603.5 & 17.55 & 0.159 & -0.135 & 0.073 & 0.064 \\
\hline $95 \% \mathrm{lb}$ & 49.73 & 2164.52 & 1.052 & 2594.9 & 17.47 & 0.153 & -0.138 & 0.070 & 0.062 \\
\hline $95 \%$ ub & 49.91 & 2191.08 & 1.061 & 2614.8 & 17.60 & 0.165 & -0.132 & 0.077 & 0.066 \\
\hline
\end{tabular}

Table A 2: New 4E parameters along with bootstrapped mean, 95\% lower bound and 95\% upper bound confidence intervals

\begin{tabular}{|c|c|c|c|c|c|c|c|c|c|}
\hline & \multicolumn{9}{|c|}{ Parameters } \\
\hline & {$\left[\mathrm{cm}^{3} / \mathrm{mol}\right]$} & $\Gamma[\mathrm{K}]$ & $c_{1}$ & $\varepsilon / \mathrm{R}[\mathrm{K}]$ & $\beta 10^{3}$ & $\mathrm{k}_{\mathrm{ij}} \mathrm{CH}_{4}$ & $\mathrm{k}_{\mathrm{ij}} \mathrm{H}_{2} \mathrm{O}$ & $k_{i j} n-C_{6}$ & $k_{i j} n-C_{7}$ \\
\hline Set: 4E & 50.14 & 2297.11 & 0.883 & 2224.7 & 12.74 & 0.126 & -0.054 & 0.048 & 0.036 \\
\hline Bootstrap $\mu$ & 50.18 & 2296.56 & 0.884 & 2224.4 & 12.72 & 0.127 & -0.054 & 0.048 & 0.037 \\
\hline $95 \% \mathrm{lb}$ & 50.09 & 2289.13 & 0.881 & 2220.9 & 12.64 & 0.123 & -0.057 & 0.046 & 0.035 \\
\hline $95 \%$ ub & 50.29 & 2301.41 & 0.890 & 2228.0 & 12.76 & 0.131 & -0.051 & 0.051 & 0.039 \\
\hline
\end{tabular}

Table A 3: New 4F parameters along with bootstrapped mean, 95\% lower bound and 95\% upper bound confidence intervals

\begin{tabular}{|c|c|c|c|c|c|c|c|c|c|}
\hline & \multicolumn{9}{|c|}{ Parameters } \\
\hline & {$\left[\mathrm{cm}^{3} / \mathrm{mol}\right]$} & $\Gamma[\mathrm{K}]$ & $c_{1}$ & $\varepsilon / R[K]$ & $\beta 10^{3}$ & $\mathrm{k}_{\mathrm{ij}} \mathrm{CH}_{4}$ & $\mathrm{k}_{\mathrm{ij}} \mathrm{H}_{2} \mathrm{O}$ & $k_{i j} n-C_{6}$ & $k_{i j} n-C_{7}$ \\
\hline Set: $4 \mathrm{~F}$ & 50.02 & 2407.04 & 0.806 & 2347.7 & 11.99 & 0.130 & -0.023 & 0.052 & 0.041 \\
\hline Bootstrap $\mu$ & 50.08 & 2405.18 & 0.809 & 2347.4 & 11.96 & 0.132 & -0.024 & 0.052 & 0.041 \\
\hline $95 \% \mathrm{lb}$ & 49.98 & 2393.44 & 0.805 & 2342.1 & 11.86 & 0.128 & -0.028 & 0.050 & 0.039 \\
\hline $95 \%$ ub & 50.22 & 2411.52 & 0.818 & 2352.4 & 12.01 & 0.136 & -0.021 & 0.055 & 0.043 \\
\hline
\end{tabular}

Table A 4 New 4C parameters along with bootstrapped mean, 95\% lower bound and 95\% upper bound confidence intervals

\begin{tabular}{|c|c|c|c|c|c|c|c|c|c|}
\hline & \multicolumn{9}{|c|}{ Parameters } \\
\hline & {$\left[\mathrm{cm}^{3} / \mathrm{mol}\right]$} & $\Gamma[K]$ & $C_{1}$ & $\varepsilon / \mathrm{R}[\mathrm{K}]$ & $\beta 10^{3}$ & $\mathrm{k}_{\mathrm{ij}} \mathrm{CH}_{4}$ & $\mathrm{k}_{\mathrm{ij}} \mathrm{H}_{2} \mathrm{O}$ & $k_{i j} n-C_{6}$ & $k_{i j} n-C_{7}$ \\
\hline Set: $4 C$ & 49.84 & 2542.30 & 0.650 & 2385.6 & 14.55 & 0.134 & -0.113 & 0.049 & 0.036 \\
\hline Bootstrap $\mu$ & 49.94 & 2541.44 & 0.652 & 2384.9 & 14.53 & 0.136 & -0.114 & 0.050 & 0.037 \\
\hline $95 \% \mathrm{lb}$ & 49.80 & 2531.56 & 0.648 & 2379.9 & 14.40 & 0.133 & -0.118 & 0.047 & 0.035 \\
\hline $95 \%$ ub & 50.16 & 2548.73 & 0.660 & 2388.6 & 14.59 & 0.140 & -0.112 & 0.052 & 0.039 \\
\hline
\end{tabular}


Table A 5: Error data for Figures 13-16

\begin{tabular}{|c|c|c|c|c|c|c|c|c|}
\hline & & & & Data fit er & [\% ARD] & & & \\
\hline & $\mathbf{P}_{\text {Sat }}$ & $\rho$ & $\mathrm{TPx}\left(\mathrm{H}_{2} \mathrm{O}\right)$ & $\operatorname{TPy}\left(\mathrm{H}_{2} \mathrm{O}\right)$ & $\operatorname{TPx}\left(\mathrm{C}_{1}\right)$ & $\operatorname{TPy}\left(C_{1}\right)$ & $\left(\mathrm{nC}_{6}\right)$ & $\left(\mathrm{nC}_{7}\right)$ \\
\hline $4 C$ - Lit & 1.96 & 2.44 & 4.40 & 11.1 & 12.8 & 23.5 & 8.69 & 3.24 \\
\hline Set: $3 C$ & 0.97 & 0.29 & 1.87 & 6.64 & 5.46 & 18.2 & 6.93 & 6.50 \\
\hline Average & 0.99 & 0.31 & 1.86 & 6.67 & 5.55 & 18.3 & 7.42 & 6.76 \\
\hline $95 \% \mathrm{lb}$ & 0.95 & 0.28 & 1.73 & 6.06 & 5.37 & 17.5 & 5.66 & 6.46 \\
\hline $95 \%$ ub & 1.07 & 0.42 & 2.07 & 7.37 & 6.11 & 19.3 & 10.2 & 7.72 \\
\hline Set: 4E & 1.13 & 0.48 & 2.14 & 10.0 & 3.67 & 16.5 & 4.02 & 7.74 \\
\hline Average & 1.14 & 0.50 & 2.14 & 10.1 & 3.75 & 16.5 & 4.23 & 7.83 \\
\hline $95 \% \mathrm{lb}$ & 1.08 & 0.48 & 2.02 & 9.00 & 3.55 & 16.0 & 3.87 & 6.88 \\
\hline $95 \%$ ub & 1.28 & 0.58 & 2.30 & 11.3 & 4.30 & 17.1 & 5.54 & 8.90 \\
\hline Set: 4F & 1.32 & 0.47 & 2.00 & 10.5 & 3.71 & 16.9 & 4.05 & 8.16 \\
\hline Average & 1.31 & 0.48 & 1.94 & 10.3 & 3.86 & 17.1 & 4.30 & 8.31 \\
\hline $95 \% \mathrm{lb}$ & 1.23 & 0.46 & 1.77 & 8.91 & 3.65 & 16.5 & 3.88 & 7.19 \\
\hline $95 \%$ ub & 1.45 & 0.55 & 2.10 & 11.3 & 4.42 & 17.8 & 5.77 & 9.88 \\
\hline Set: 4C & 1.10 & 0.66 & 2.28 & 5.2 & 2.79 & 19.6 & 8.95 & 3.11 \\
\hline Average & 1.10 & 0.61 & 2.27 & 5.2 & 2.94 & 19.7 & 9.16 & 3.34 \\
\hline $95 \% \mathrm{lb}$ & 1.05 & 0.55 & 2.06 & 4.68 & 2.77 & 19.2 & 7.98 & 2.94 \\
\hline $95 \%$ ub & 1.22 & 0.74 & 2.52 & 5.7 & 3.45 & 20.4 & 10.42 & 4.20 \\
\hline
\end{tabular}

